\title{
A MODAL SEISMIC DESIGN PROCEDURE BASED ON A SELECTED LEVEL OF DUCTILITY DEMAND
}

\author{
Milad Farahanchi Baradaran ${ }^{1}$ and Farhad Behnamfar ${ }^{2}$
}

(Submitted August 2018; Reviewed December 2018; Accepted February 2019)

\begin{abstract}
Determination of seismic design forces of structures is performed by the building codes usually using response reduction (or behaviour) factors that incorporate indeterminacy and ductility capacity of lateral bearing systems. In this procedure story drifts are checked as a final design step approximately preventing stories from assuming excessive ductility demands, or seismic damage. If this procedure is reversed, a more logical seismic design approach may be developed by starting with a ductility-controlled procedure. It is the incentive of this research in which by using a large number of earthquakes, first nonlinear acceleration spectra are developed for different levels of ductility demand. Then an energy-based modal procedure is developed in which the system ductility demand is distributed between the important vibration modes based on their contribution. Finally, the developed method is applied to seismic design of several buildings selected from both regular and irregular structural systems. Comparison with a sample code design establishes success of the method in developing a more rational seismic design.
\end{abstract}

\section{INTRODUCTION}

Design of structures in seismic prone areas has been traditionally performed by determining the equivalent lateral forces as a first step. In calculation of the forces, the plastic (or dynamic) indeterminacy and the ductility capacity of the lateral load bearing system of building are inherently taken into account, collectively within a response modification or $\mathrm{R}$ factor in most building codes. Generally, the designer has no option but only to use a ready R-factor. The R-factor is reduced by the code directly or indirectly in two cases, for important buildings and for buildings with less-than-usual indeterminacy to account approximately for a smaller level of allowable seismic damage. After a first round of member proportioning, the story drifts are checked to see again approximately if the story ductility demand, or seismic damage, is within the accepted limits. In all, this is a procedure that tries to balance the required stiffness/strength of members with their ductility demand, where reduction of one results in increase of the other. Therefore, the method is iterative in nature. The fact that if the story drift is small the member strengths can be reduced without violating the required gravity strength and story drift limit (and the serviceability level earthquake shaking demands, where applicable), is neglected in this procedure.

It is well known that accepting a certain level of seismic damage, without collapse, is inevitable for an economic, and safe, design in seismic areas. Then it sounds logical that one selects a desired level of seismic damage, or ductility demand, for a certain building and then calculates the required stiffness/strength of building associated with the selected ductility. This procedure is exactly reverse of what is currently being implemented within the force-based seismic design codes. This is perhaps due to the fact that the building codes have been written primarily for design under gravity loads where only stiffness and strength are important. Many attempts have been undertaken to develop new design procedures specific to earthquake loads based on limiting plastic deformations and damage. Generally, the goal of these procedures is to keep the ductile members, or seismic "fuses", from being over-deformed in the plastic range, and to prevent the non-ductile members from assuming any plastic deformation. This is called a performance-based design. A summary of the more relevant efforts undertaken in the last 15 years is given below.

Bertero, R. and V.V. Bertero [1] proposed a comprehensive seismic design approach based on performance. They presented certain performance levels under specific levels of seismic hazard with known probabilities of exceedance. They used the Park-Ang damage index [2] as a tool for quantifying the seismic damage. Also, they developed inelastic spectra for acceleration and displacement based on ductility demand. Medhekar and Kennedy [3] presented inelastic displacement spectra as functions of an equivalent damping ratio that included both viscous and hysteresis damping. They calculated the design base shear associated with an effective period consistent with the required lateral deformation and stiffness of structure.

Borzi et al. [4] also developed inelastic displacement spectra for perfect elasto-plastic and for hysteresis stiffened-softened lateral behaviours. Chopra and Goel [5] discussed the essential aspects of a direct displacement-based design using elastic and inelastic design spectra. Their method included calculating an equivalent damping ratio based on the selected ductility demand and calculating the required period, stiffness and base shear. The drawback in their work was that the final design might not fulfil the required ductility level resulting in the need for iteration

Kim and Seo [6] proposed a displacement-based design procedure and evaluated it specifically for design of nonbuckling braces in steel structures. The overall procedure was similar to the previously mentioned algorithms. Christopoulos and Pampanin [7] based their work on limiting the permanent residual displacements after occurrence of the design earthquake. They developed inelastic design spectra for permanent deformations as a function of maximum elastic deformation and the fundamental period. Choi and Kim [8] suggested use of hysteretic energy and cumulative ductility spectra for seismic design and applied it to braced frames.

${ }^{1}$ MSc Graduate, Department of Civil Engineering, Isfahan University of Technology, Esfahan 8415683111, Iran. Email: miladfarahanchi@yahoo.com

${ }^{2}$ Corresponding Author, Associate professor, Department of Civil Engineering, Isfahan University of Technology, Esfahan 8415683111, Iran. Email:farhad@cc.iut.ac.ir 
Priestley et al. [9] presented a direct displacement-based design using an effective period, a required ductility level and equivalent damping, and inelastic displacement spectra.

Sahoo and Chao [10] presented a plastic design procedure based on seismic performance. Their methodology was different in the aspect that they began from assuming a desired plastic mechanism in the structure and determined the required strength for limiting the plastic hinge deformations, and the selected target displacement. A similar approach was also undertaken by Grigorian and Grigorian [11] in which they based their method on formation of plastic hinges primarily in beams, a uniform distribution of demand-capacity ratio in members, and a pre-selected distribution of story drifts. In similar works, Wongpakdee et al. [12] and Banihashemi et al. [13] presented seismic design procedures based on a known plastic mechanism. Vamvatsikos and Aschheim [14] proposed a yield frequency spectrum to calculate the story shear strength based on selected performance goals. The mentioned spectra give the seismic coefficient as a function of the required ductility for different hazard levels.

Among the seismic design codes, perhaps that of New Zealand [15] is the only code that is based on the desired ductility demand rather than the R-factor. Also, the document NEHRP 2009 [16] in each appendix uses the target displacement and desired ductility and plastic mechanism as a framework for performance-based design. The yield point spectrum is the main tool for determining the associated base shear in this method giving the yield strength based on the required ductility and period.

In summation, the existing methods for seismic design based on deformation or performance whether use the inelastic spectra based only on the fundamental mode, or utilize a plastic mechanism that is difficult to guess and develop. In this study, use of the plastic mechanism is put aside while inelastic acceleration spectra are developed and a modal procedure is proposed to determine the share of each mode in providing for the total ductility demand.

\section{THE INELASTIC SINGLE DEGREE OF FREEDOM SYSTEM}

To develop the inelastic acceleration spectra to be used in the later phases of this study, a single degree of freedom (SDF) system is considered. The inelastic action in this system is considered using a bilinear force-displacement path with a positive post-yield slope (Figure 1). Such a lateral behaviour is representative of systems with no considerable strength reduction up to large displacements specific to ductile seismic resistant structures not prone to P-Delta effects. A representative value of 0.03 is assumed for the post-yield to elastic stiffness ratio, $\alpha$.

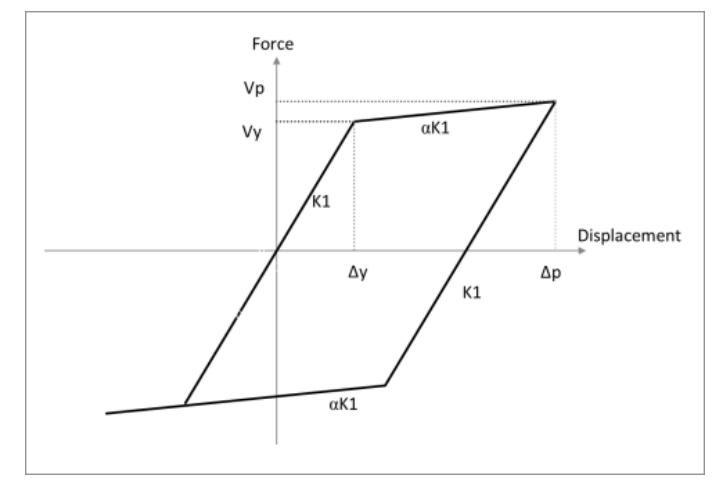

Figure 1: The bilinear force-displacement path.
The value assumed for $\alpha$ mostly represents steel structures. The lateral stiffness and strength of the above system are determined using its natural period and the desired ductility demand.

The load-deformation path presumed for the system does not make a limitation for the higher mode responses for two reasons. First, in most cases, response of the higher modes is limited in the first branch (linear) behaviour because the displacement amplitudes are much smaller in the higher modes. Second, the mentioned path only shows the overall behaviour of the whole system. In design, it is translated to nonlinear behaviour at the section level.

\section{THE GROUND MOTION SELECTION AND PREPARATION PROCEDURE}

Inelastic acceleration spectra are to be calculated for the system of Figure 1 using suitable earthquake ground motions. The seismic records are selected both within the near and far field motions separately to retain generality. They are assumed to have been recorded on firm ground (soil type B [16]) and to have large enough magnitudes. Characteristics of the selected ground motions are listed in Tables 1 and 2.

It is to be noted that when an earthquake recorded at several stations is encountered, only the one with the largest square root of sum of the squares (SRSS) of the peak ground accelerations (PGA's) in horizontal directions $\mathrm{H}_{1}$ and $\mathrm{H}_{2}$ is used to prevent bias.

Table 1: General properties of the selected ground motions from PEER NGA database [17].

\begin{tabular}{cccc}
$\begin{array}{c}\text { Earthquak } \\
\text { e type }\end{array}$ & $\begin{array}{c}\text { Magnitude, } \\
\boldsymbol{M}\end{array}$ & $\begin{array}{c}\text { Shear wave } \\
\text { velocity in } \\
\text { soil, } \boldsymbol{V}_{\boldsymbol{s}}(\mathbf{m} / \mathbf{s})\end{array}$ & $\begin{array}{c}\text { Focal } \\
\text { distance, } \boldsymbol{R}_{\boldsymbol{j} \boldsymbol{b}} \\
\mathbf{( \mathbf { k m } )}\end{array}$ \\
\hline Near field & & Type B & $0<R_{j b} \leq 20$ \\
Far field & $6 \leq M \leq 8$ & $375 \leq V_{s} \leq 750$ & $\begin{array}{l}20<R_{j b} \\
\leq 50\end{array}$ \\
\hline
\end{tabular}

Table 2: Characteristics of the ground motions (to be continued).

\begin{tabular}{ccccc} 
& \multirow{2}{*}{ Order } & $\begin{array}{c}\text { Record } \\
\text { number }\end{array}$ & Earthquake name & \multicolumn{2}{c}{ PGA (g) } \\
\cline { 4 - 5 } & & H1 & H2 \\
\hline 1 & RSN-1 & Helena & 0.464 & 0.483 \\
2 & RSN-33 & Parkfield & 0.14 & 0.207 \\
3 & RSN-71 & San Fernando & 0.134 & 0.21 \\
4 & RSN-125 & Friuli & 0.86 & 0.809 \\
5 & RSN-139 & Tabas & 0.18 & 0.159 \\
6 & RSN-164 & Imperial Valley & 0.221 & 0.155 \\
7 & RSN-230 & Mammoth Lakes & 0.183 & 0.22 \\
8 & RSN-265 & Victoria & 0.232 & 0.179 \\
9 & RSN-292 & Irpinia & 0.11 & 0.081 \\
10 & RSN-451 & Morgan Hill & 0.24 & 0.254 \\
11 & RSN-495 & Nahanni & 0.091 & 0.164 \\
12 & RSN-540 & N. Palm Springs & 0.277 & 0.195 \\
\hline
\end{tabular}


Table 2: Characteristics of the ground motions (Continued).

\begin{tabular}{|c|c|c|c|c|}
\hline \multirow[t]{2}{*}{ Order } & \multirow{2}{*}{$\begin{array}{l}\text { Record } \\
\text { number }\end{array}$} & \multirow{2}{*}{$\begin{array}{l}\text { Earthquake } \\
\text { name }\end{array}$} & \multicolumn{2}{|c|}{ PGA (g) } \\
\hline & & & H1 & $\mathrm{H} 2$ \\
\hline 13 & RSN-550 & Chalfant Valley & 0.098 & 0.103 \\
\hline 14 & RSN-564 & Kalamata & 0.111 & 0.118 \\
\hline 15 & RSN-587 & New Zealand & 0.189 & 0.229 \\
\hline 16 & RSN-779 & Loma Prieta & 0.06 & 0.08 \\
\hline 17 & RSN-825 & Cape Mendocino & 0.119 & 0.164 \\
\hline 18 & RSN-864 & Landers & 0.514 & 0.568 \\
\hline 19 & RSN-901 & Big Bear & 0.11 & 0.092 \\
\hline 20 & $\begin{array}{l}\text { RSN- } \\
1004\end{array}$ & Northridge & 0.059 & 0.066 \\
\hline 21 & $\begin{array}{l}\text { RSN- } \\
1111\end{array}$ & Kobe & 0.156 & 0.161 \\
\hline 22 & $\begin{array}{l}\text { RSN- } \\
1126\end{array}$ & Kozani & 0.273 & 0.357 \\
\hline 23 & $\begin{array}{l}\text { RSN- } \\
1148\end{array}$ & Kocaeli & 0.282 & 0.382 \\
\hline 24 & $\begin{array}{l}\text { RSN- } \\
1231\end{array}$ & Chi-Chi & 0.315 & 0.357 \\
\hline 25 & $\mathrm{RSN}-15$ & Kern County & 0.409 & 0.324 \\
\hline 26 & RSN-87 & San Fernando & 0.157 & 0.168 \\
\hline 27 & RSN-288 & Irpinia & 0.442 & 0.419 \\
\hline 28 & RSN-359 & Coalinga & 0.633 & 0.645 \\
\hline 29 & $\mathrm{RSN}-450$ & Morgan Hill & 0.321 & 0.227 \\
\hline 30 & RSN-534 & N. Palm Springs & 1.303 & 0.713 \\
\hline 31 & RSN-552 & Chalfant Valley & 1.201 & 1.108 \\
\hline 32 & RSN-787 & Loma Prieta & 0.63 & 0.481 \\
\hline 33 & RSN-814 & Griva & 0.161 & 0.166 \\
\hline 34 & RSN-818 & Georgia & 0.272 & 0.239 \\
\hline 35 & RSN-830 & Cape Mendocino & 0.241 & 0.284 \\
\hline 36 & RSN-897 & Landers & 0.607 & 0.57 \\
\hline 37 & RSN-935 & Big Bear & 1.039 & 1.494 \\
\hline 38 & RSN-963 & Northridge & 0.284 & 0.274 \\
\hline 39 & $\begin{array}{l}\text { RSN- } \\
1102\end{array}$ & Kobe & 0.545 & 0.481 \\
\hline 40 & $\begin{array}{l}\text { RSN- } \\
1139\end{array}$ & Dinar & 0.932 & 0.753 \\
\hline
\end{tabular}

In the next step, the selected records are categorized based on their PGA's as of Table 3. The records of each category are scaled such that their PGA is equal to the median PGA in each category. For averaging purposes, when number of records in a category is less than 7, it is accommodated with a necessary number of records borrowed from neighbouring categories with scaling. On the other hand, when both of the horizontal components of an earthquake exist in the same interval, the one with smaller PGA is removed. In total, 84 records are used for nonlinear dynamic analysis of the system of Figure 1.
Table 3: Number of accelerograms in each interval.

\begin{tabular}{ccc} 
& \multicolumn{2}{c}{ Number of records } \\
\cline { 2 - 3 } Interval of PGA (g) & Recorded & Scaled \\
\hline $0.05-0.15$ & 17 & 10 \\
$0.15-0.25$ & 24 & 17 \\
$0.25-0.35$ & 11 & 8 \\
$0.35-0.45$ & 6 & 7 \\
$0.45-0.55$ & 6 & 7 \\
$0.55-0.65$ & 6 & 7 \\
$0.65-0.75$ & 1 & 7 \\
$0.75-0.85$ & 2 & 7 \\
$0.85-0.95$ & 2 & 7 \\
$0.95-1.05$ & 5 & 7 \\
Total & - & 84 \\
\hline
\end{tabular}

\section{RESULTS OF THE NONLINEAR DYNAMIC} ANALYSIS

The maximum acceleration of the SDF system of Figure 1 is calculated under the scaled ground motions for the fundamental periods of 0.1-3.0 s with $0.1 \mathrm{~s}$ increments and for the ductility demands 1-6 with increments of 0.5 . This quantity can be thought of as being equivalent to $S_{a} / R$ where $S_{a}$ is the elastic maximum acceleration of the system. Therefore, this value can be used directly in the seismic design without use of R. The OpenSees software [18] is used for this purpose. The results are presented versus a PGA equal to the median PGA in each interval, system period, and ductility demand in Figure 2.

The ductility demand is the ratio of the maximum displacement $\Delta_{\mathrm{p}}$ to the yield displacement $\Delta_{\mathrm{y}}$ in Figure 1, while both of the mentioned deformations are unknown under a given earthquake. Therefore, since the design parameters are presented in Figs. 2 and 3 versus certain ductility demands, the nonlinear analysis has to be iterated in each case by changing $\Delta_{\mathrm{y}}$ in order to reach at the selected ductility factor.

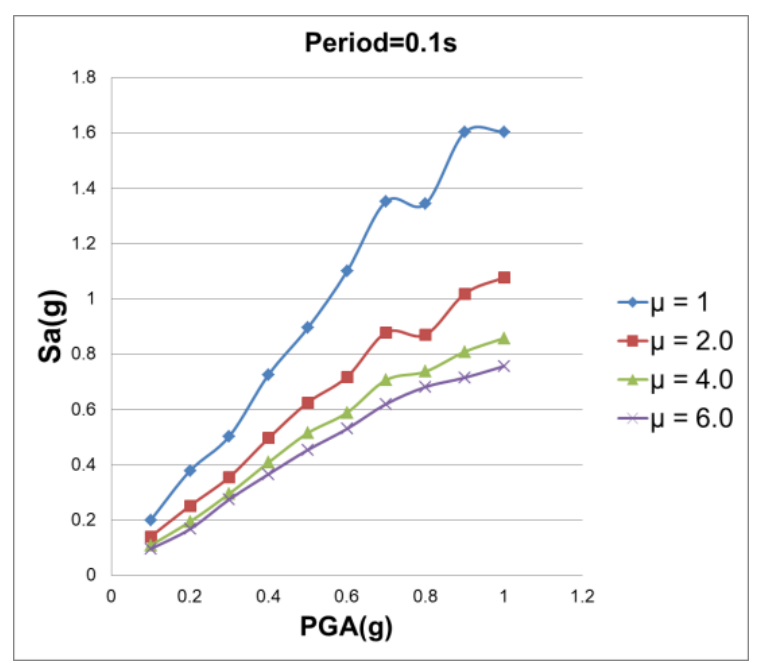

Figure 2: Maximum acceleration response of the SDOF system. 


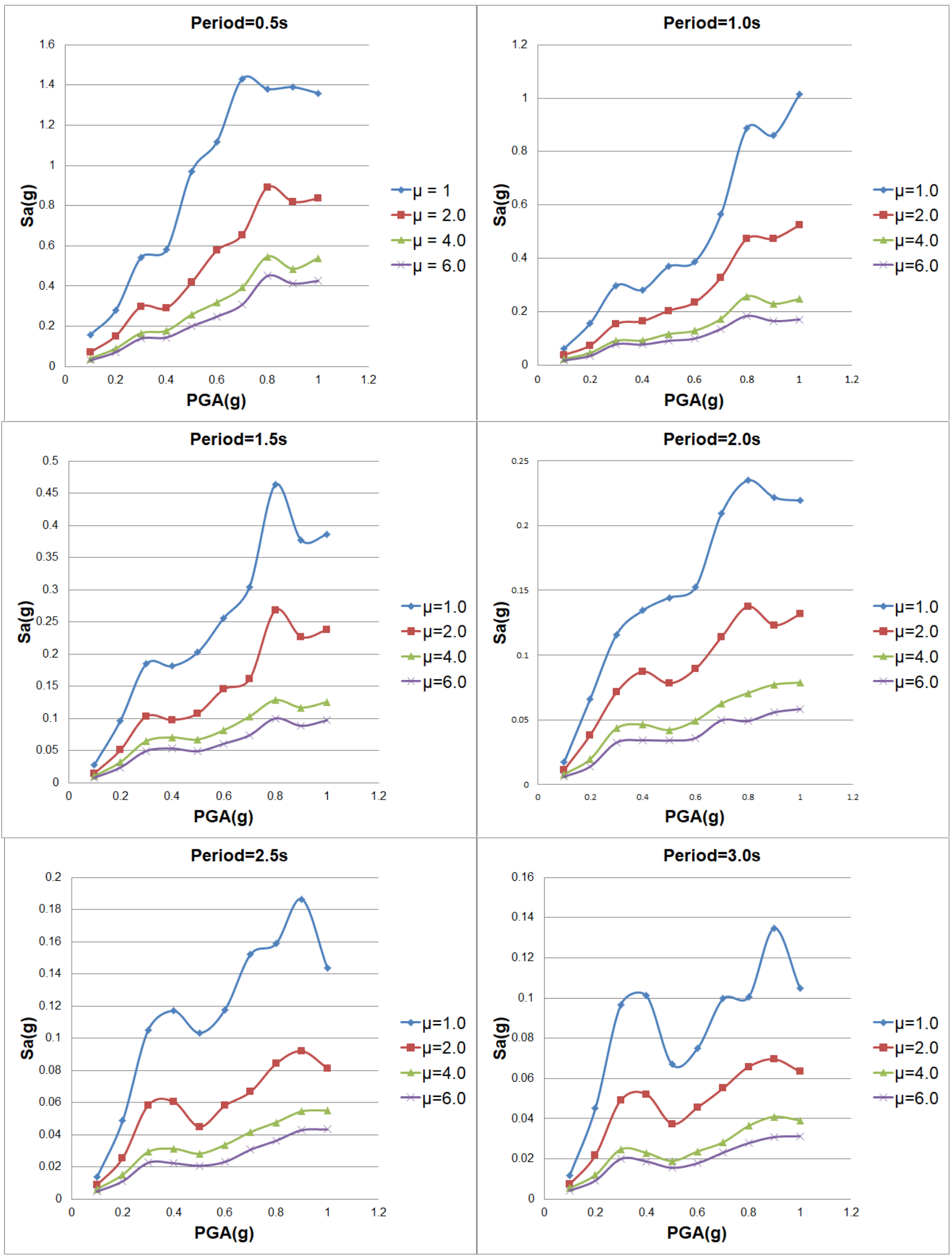

Figure 2: Maximum acceleration response of the SDF system (Continued).

Figure 2 shows that at a certain ductility level, the maximum acceleration response increases with PGA, as expected. Moreover, the acceleration response decreases with increasing ductility at a certain period and PGA. The response has a decreasing trend with increasing periods, which is usual.

It is to be noted that number of nonlinear dynamic analysis in producing Figure 2 is 27,720 consisting of analysis with 84 records for 30 periods at 11 levels of ductility.
In the next step, the maximum acceleration responses are averaged at each period for each PGA. This is justified because at least 7 records exist in each interval [16]. Then, the inelastic maximum acceleration responses at larger ductility are normalized to those corresponding to elastic response, i.e. unit ductility, for the same period and PGA. The ratio is called $a_{p}$ and is shown in Figure 3. Values of $a_{p}$ are given in the appendix as Table A.11. 


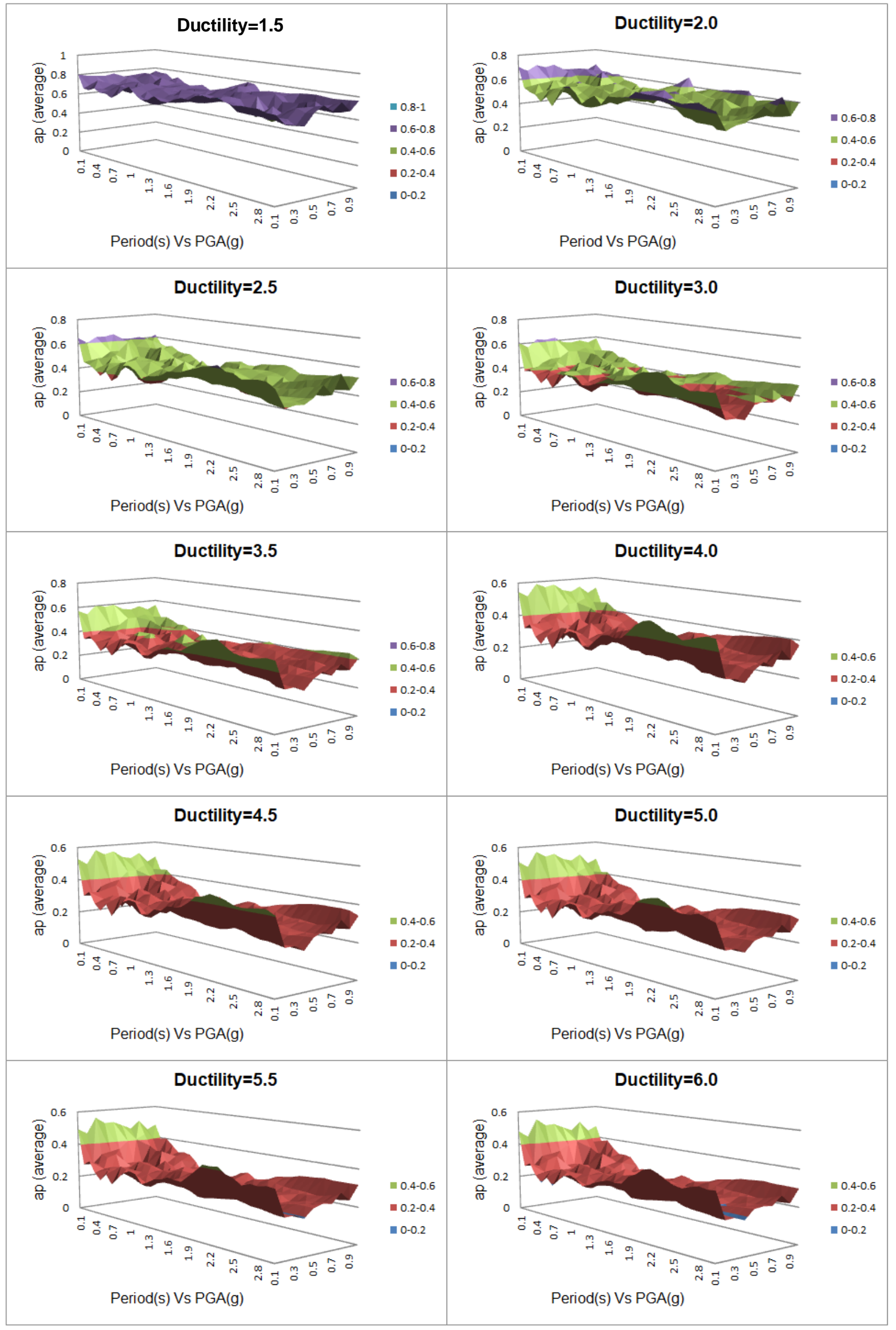

Figure 3: Ratio of the inelastic maximum acceleration responses to the corresponding elastic responses, $a_{p}$. 
As observed in Figure 3, $a_{p}$ is always smaller than 1 and decreases with increase of period and ductility, as expected.

\section{THE PROPOSED MODAL ANALYSIS BASED ON DUCTILITY DEMAND}

The essential requirement for implementation of the proposed method of directly using the maximum inelastic acceleration in design is determination of the ductility demand in each mode.

The equivalent approach in the code-based spectral analysis is calculating the spectral acceleration in each mode and dividing by the same R-factor in all of the important modes, as if extent of the nonlinear action is the same in various modes. This is only an approximate approach followed by the code for simplicity. However, in the current study concentration of inelastic action in the lower modes is considered using an energy approach as follows.

The total vibration energy at each time instant, E, can be written as the sum of kinetic and potential energies in Eq. (1):

$$
E=\frac{1}{2} \dot{u}^{T} m \dot{u}+\frac{1}{2} u^{T} k u
$$

in which $u$ is the vector of modal deformations, and $m$ and $k$ are the mass and stiffness matrices. Also a dot represents a time derivation and the superscript $T$ shows transpose of a vector/matrix. In modal analysis, the response vector $u$ is decomposed into its mode shape vector $\varphi$ and modal response amplitude $q$ as follows:

$$
u=\varphi q
$$

Substitution of Eq. (2) in (1) results in the total energy being expressed in terms of the modal quantities as:

$$
E=\frac{1}{2}\left(\sum_{i=1}^{n} M_{\mathrm{i}} \dot{q}_{i}^{2}+\sum_{i=1}^{n} K_{i} q_{\mathrm{i}}^{2}\right)
$$

where the index $i$ is the mode number, $n$ is the total number of degrees of freedom (or deformation unknowns), and $M_{i}$ and $K_{i}$ are the modal mass and stiffness defined as follows:

$$
\begin{aligned}
& M_{i}=\varphi_{i}^{T} m \varphi_{i} \\
& K_{i}=\varphi_{i}^{T} k \varphi_{i}=\omega_{i}^{2} M_{i}
\end{aligned}
$$

where $\omega_{i}$ is the frequency of the $\mathrm{i}^{\text {th }}$ mode. The vibration energy in the $\mathrm{i}^{\text {th }}$ mode can be extracted from Eq. (3) as:

$$
E_{i}=\frac{1}{2} M_{i} \dot{q}_{i}^{2}+\frac{1}{2} K_{i} q_{i}^{2}=\frac{1}{2}\left(\dot{q}_{i}^{2}+\omega_{i}^{2} q_{i}^{2}\right) M_{i}
$$

The maximum value of $E_{i}$, or $E_{\text {imax }}$, can be calculated noting that:

$$
\begin{aligned}
& \dot{q}_{\text {imax }}=\omega_{i} q_{\text {imax }} \\
& q_{\text {imax }}=\Gamma_{i} S_{d i} \\
& S_{d i}=S_{a i} / \omega_{i}^{2}
\end{aligned}
$$

where a subscript "max" refers to the maximum value, $S_{d i}$ and $S_{a i}$ are the $\mathrm{i}^{\text {th }}$ mode spectral displacement and acceleration, respectively, and $\Gamma_{i}$ is the $\mathrm{i}^{\text {th }}$ mode force participation factor calculated as:

$$
\begin{aligned}
\Gamma_{i} & =\frac{L_{i}}{M_{i}} \\
L_{i} & =\phi_{i}{ }^{T} m 1
\end{aligned}
$$

and 1 is a column vector with the all entries equal to unity. Substituting Eqs. (6) and (7) in (5) results in:

$$
E_{\text {imax }}=\Gamma_{i}^{2} M_{i}\left(S_{a i}\right)^{2} / 2 \omega_{i}^{2}
$$

or using Eq. (7):

$$
E_{\text {imax }}=M_{e f f i}\left(S_{a i}\right)^{2} / 2 \omega_{i}^{2}
$$

where $M_{\text {eff } i}=L_{i}{ }^{2} / M_{i}$ is the effective mass of the $\mathrm{i}^{\text {th }}$ mode. The modal energy ratio ER is introduced in this study as:

$$
E R_{i}=E_{\text {imax }} / E_{\text {max }}
$$

where $E_{\text {max }}$ is defined as sum of $E_{\text {imax }}$ for $i=1, \ldots, n$. The value 2 in the denominators of Eqs. 8 and 9 are due to the facts that the maxima of displacement or velocity occur only when the other response is zero. If the seismic damage in a structure is introduced by a quantity called the damage index $D I$, it is assumed to be sum of the modal indices $D I_{i}$ where $D I_{i}$ is calculated by Eq. (11):

$$
D I_{i}=E R_{i} \cdot D I
$$

$D I$ is an index usually varying between $0-1$ with zero showing no damage and a unit value representing total damage or collapse of a structure. There are tens of equations proposed by different researchers for DI. Generally, these equations introduce $D I$ as a function of ductility demand only or a combination of the ductility demand and plastic energy. A relation for $D I$ containing only the ductility factor is more appropriate for the purposes of this study. Here, the equation proposed by Cosenza et al. [19] is utilized written as:

$$
D I=\frac{\mu-1}{\mu_{u}-1}
$$

where $\mu$ and $\mu_{u}$ are the ductility demand and ductility capacity at collapse. In general:

$$
\mu=\frac{\Delta_{\max }}{\Delta_{y}}
$$

where $\Delta_{\max }$ and $\Delta_{y}$ are the lateral displacements at maximum response and at yield, respectively. The ductility demand $\mu$ depends on the target performance. For instance, reference [16] recommends $\mu$ to be taken as 2.4 for special moment frames performing at life safety that corresponds to an intermediate level of damage, the same level for which normal buildings are designed based on the seismic codes.

Finally, the modal ductility demand, $\mu_{i}$, is calculated using Eqs. (11) and (12) as:

$$
\mu_{i}=1+\left(\mu_{u}-1\right) D I_{i}
$$

Using $\mu_{i}$ and the modal period $T_{i}=2 \pi / \omega_{i}$, the acceleration response ratio $a_{p}$ is determined from Figure 3 for the $\mathrm{i}^{\text {th }}$ mode and is called $a_{p i}$. Then the modal base shear $\mathrm{V}_{\mathrm{i}}$ is calculated from: 


$$
V_{i}=a_{p i} S_{a i} W_{i}
$$

where $W_{i}=M_{\text {ieff }} g$ and $g$ is the acceleration of gravity. The equivalent lateral forces with the resultant $V_{i}$ are calculated using the conventional modal analysis and used for spectral analysis of structure according to the proposed method.

\section{EXAMPLES OF APPLICATION}

Application of the proposed method is explained through representative examples.

A 6-story special steel moment frame is considered. Four examples of this building are discussed. First it is taken as a regular building. In the second to the fourth examples, irregularity is introduced in the building respectively in the plan

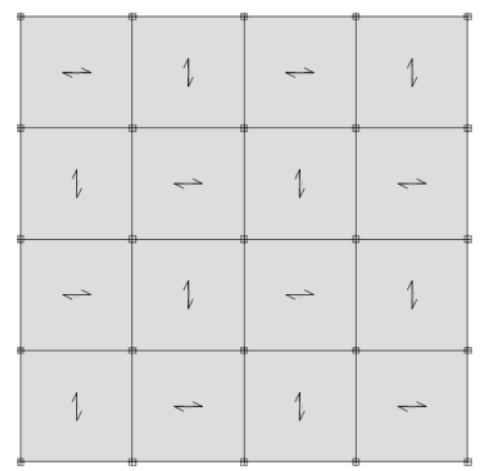

(a)

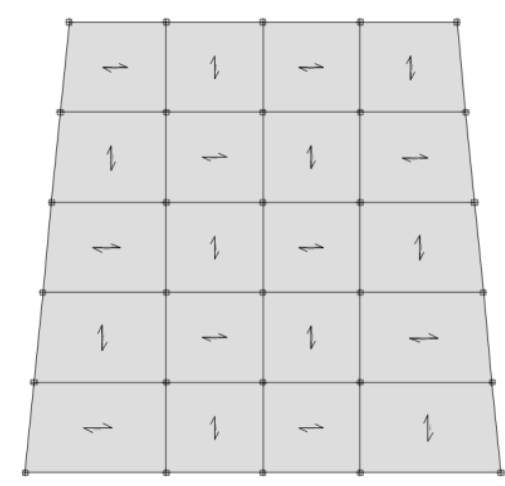

(c) geometry, mass distribution in elevation, and arrangement of the load bearing systems. The general specifications of the buildings are as follows.

The structures are residential buildings resting on a firm soil (consistent with the selected earthquakes) in a highly seismic area. The plan dimensions of the regular building are $22 \times 22 \mathrm{~m}$ with the number of bays being 4 , thus each spanning $5.5 \mathrm{~m}$. The story height is identically $3.5 \mathrm{~m}$. The dead and live loads are $600 \mathrm{kgf} / \mathrm{m}^{2}$ including partitions and $200 \mathrm{kgf} / \mathrm{m}^{2}$, respectively. The R factor and the overstrength factor $\Omega_{0}$ for the code-based design are 5 and 2.8, respectively. The story plans and elevations are shown in Figure 4.

The design spectrum for the location of the above buildings is assumed to be as Figure 5, that is consistent with a firm soil site having high seismicity

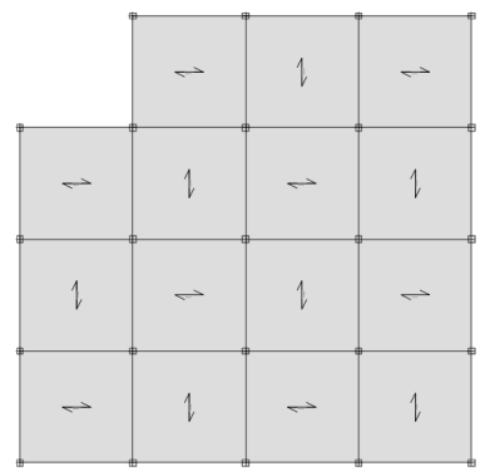

(b)

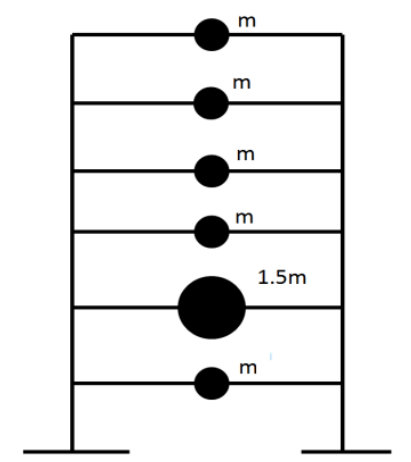

(d)

Figure 4: The 6-story building. (a) Common plan of the building regular in plan, and irregular in mass distribution along height. (b) Plan of the building with plan irregularity. (c) Plan of the building with non-perpendicular load bearing systems. (d) Mass distribution pattern of the 6-story building irregular along height.

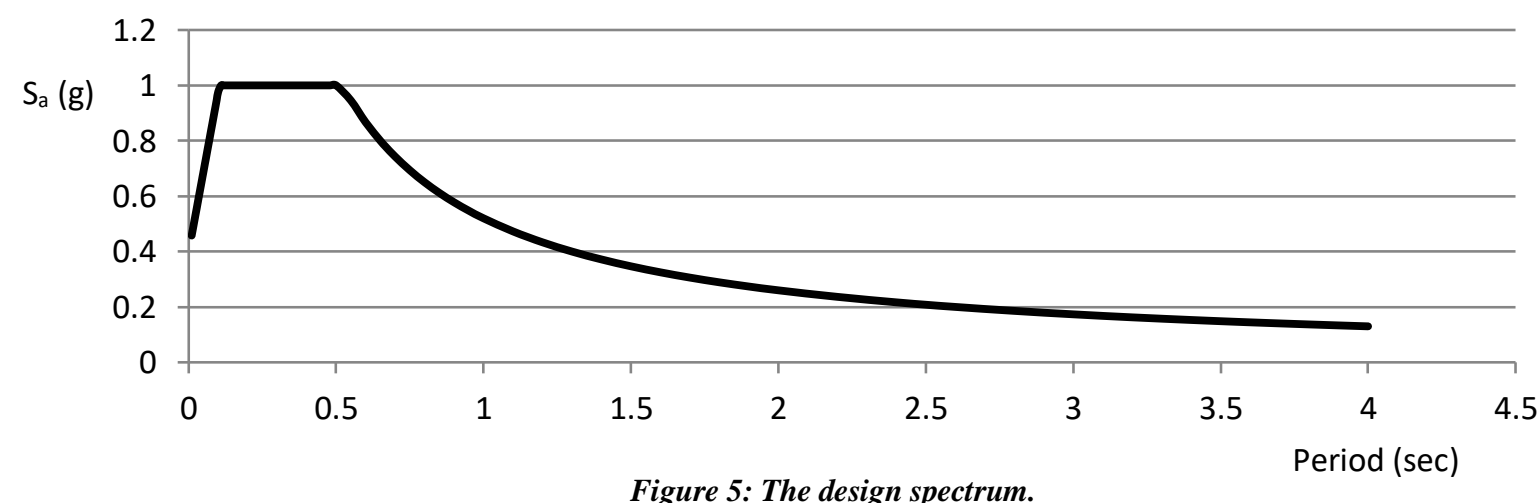

Figure 5: The design spectrum. 
The beams and columns are selected to have I and box sections, respectively. The beams prove to be IPE200 to 400 sections and the columns are $220 \times 220 \times 15$ to $280 \times 280 \times 20 \mathrm{~mm}$ in section dimensions. The specific requirements of the special steel moment frames and the limitation on the story drifts are followed in member sizing of the frames. The spectral analysis of the three-dimensional model of the above buildings with the mentioned R-factor and design spectrum results in the modal periods and base shears reported in Table 4. Six initial mode shapes of the regular 6-story building are shown in the appendix.

Table 4: Results of the conventional spectral analysis.

\begin{tabular}{|c|c|c|c|c|c|c|c|}
\hline \multicolumn{4}{|c|}{ Building type :Regular } & \multicolumn{4}{|c|}{ Building type : Irregular in plan } \\
\hline $\begin{array}{c}\text { Mode } \\
\text { number }\end{array}$ & $T_{i}(\mathrm{sec})$ & $W_{i} / W$ & $V_{i}$ (tons) & $\begin{array}{c}\text { Mode } \\
\text { number }\end{array}$ & $T_{i}(\mathrm{sec})$ & $W_{i} / W$ & $V_{i}$ (tons) \\
\hline 1 & 2.40 & 0.78 & 94.2 & 1 & 2.24 & 0.78 & 94 \\
\hline 2 & 0.80 & 0.12 & 44.1 & 2 & 0.73 & 0.12 & 45 \\
\hline 3 & 0.43 & 0.04 & 20.1 & 3 & 0.38 & 0.05 & 20 \\
\hline 4 & 0.28 & 0.03 & 13.1 & 4 & 0.24 & 0.03 & 13 \\
\hline 5 & 0.21 & 0.01 & 5.9 & 5 & 0.17 & 0.01 & 6 \\
\hline 6 & 0.15 & 0.01 & 5.2 & 6 & 0.13 & 0.01 & 5 \\
\hline \multicolumn{4}{|c|}{ Building type : Irregular in height } & \multicolumn{4}{|c|}{ Building type : Non-perpendicular } \\
\hline $\begin{array}{c}\text { Mode } \\
\text { number }\end{array}$ & $T_{i}(\mathrm{sec})$ & $W_{i} / W$ & $V_{i}$ (tons) & $\begin{array}{c}\text { Mode } \\
\text { number }\end{array}$ & $T_{i}(\mathrm{sec})$ & $W_{i} / W$ & $V_{i}$ (tons) \\
\hline 1 & 2.18 & 0.78 & 113 & 1 & 2.16 & 0.76 & 144 \\
\hline 2 & 0.79 & 0.15 & 59 & 2 & 0.72 & 0.12 & 71 \\
\hline 3 & 0.43 & 0.03 & 17 & 3 & 0.38 & 0.04 & 30 \\
\hline 4 & 0.27 & 0.02 & 10 & 4 & 0.24 & 0.03 & 19 \\
\hline 5 & 0.21 & 0.01 & 7 & 5 & 0.18 & 0.01 & 10 \\
\hline 6 & 0.16 & 0.01 & 6 & 6 & 0.13 & 0.01 & 9 \\
\hline
\end{tabular}

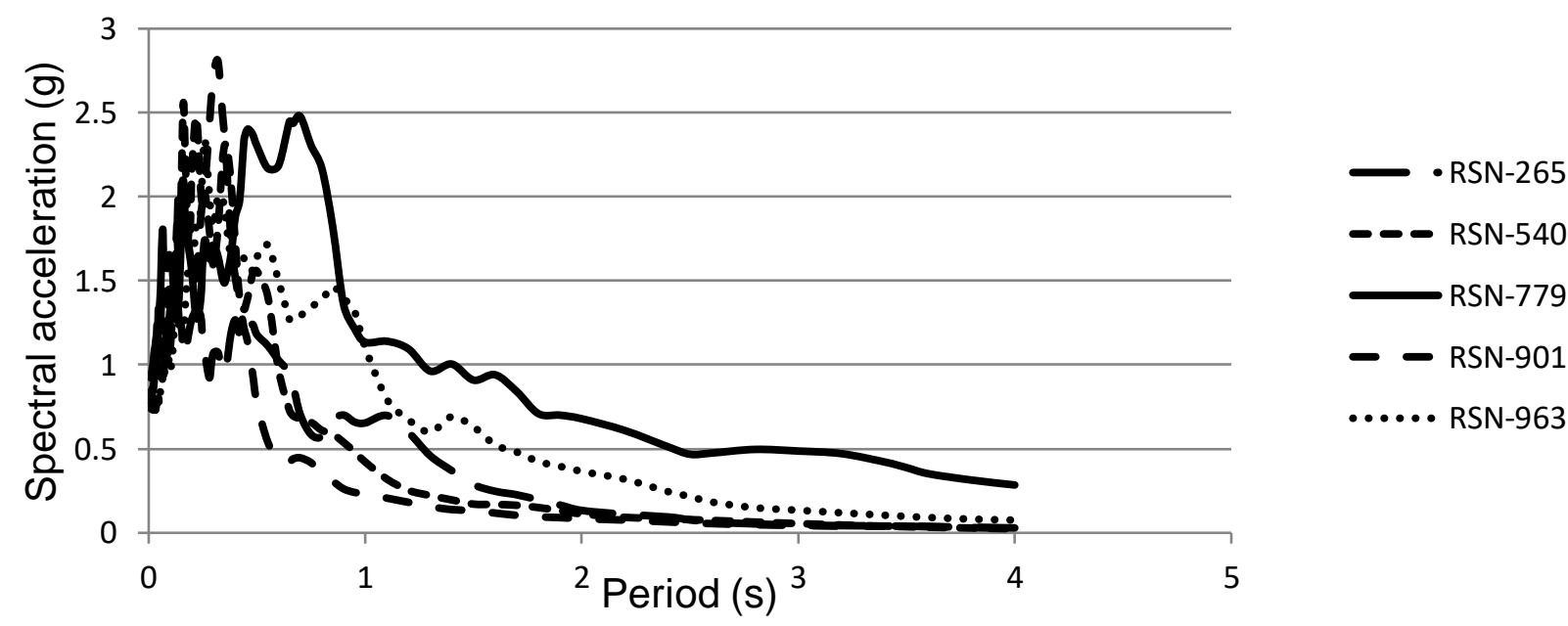

Figure 6. Response spectra of the selected earthquakes.

In the proposed method, first, one needs the parameter PGA to be used in Figure 3 for calculating $a_{p}$. The procedure used in this study is that consistent with the design spectrum of Figure 5 , earthquake records belonging to a highly seismic zone, say those listed under the PGA interval $0.55-0.65 \mathrm{~g}$ in Table 3, are picked up. The average response spectrum of this group of earthquakes is scaled such that in the period range of $0.2 \mathrm{~T}_{1^{-}}$ $1.5 T_{1}$, where $T_{1}$ is the fundamental period, it is not lower than the design spectrum. The average PGA of the selected group is multiplied by the scale factor and is used as the reference PGA for calculation of $a_{p i}$ at each modal period $\mathrm{T}_{\mathrm{i}}$. Application of the above procedure results in the response spectra of Figure 6 and a scale factor of 1.3. The parameter RSN in this figure stands for the Record Serial Number in the database.

Value of the modal ductility demand $\mu_{i}$ is also needed to fulfill this requirement. The following steps are taken to calculate $\mu_{i}$ for each mode. In Eq. (12) a value, say 0.5, is assumed for each $D I$ consistent with the damage extent at the life safety level. The total ductility demand, $\mu$, is assumed to be 2.4 according to the recommendation of [16] for this type of buildings. Then from Eq. (12): $\mu_{u}=3.8$. Then, from Eq. (14): $\mu_{i}=1+2.8 D I_{i}$ and from Eq. (11): $D I_{i}=0.5 E R_{i}$ and $E R_{i}$ is calculated from Eqs. (9) and (10).

After determining $a_{p i}$ from Figure 3 based on the values of PGA, $T_{i}$, and $\mu_{i}$, it is used in Eq. (15) to determine the ith mode base shear $V_{i}$. Rest of the modal analysis and design of the structures is identical to the conventional procedure. In other words, the modal base shears are combined using the SRSS (or the CQC) rule to arrive at the total design base shear. It is then distributed along height of the building as lateral forces acting at floor levels. The structure is analysed under these equivalent lateral forces and the results are combined with those under gravity loads to be used in structural members' design. Details of the calculations are mentioned in Tables 5-8, where $T^{\prime}{ }_{i}$ is the final period after design. 
Table 5: Calculation of the modal base shears for the regular building (DI=0.5).

\begin{tabular}{|c|c|c|c|c|c|c|c|}
\hline Mode number & $T_{i}(\mathrm{sec})$ & $E R_{i}$ & $D I_{i}$ & $\mu_{i}$ & $a_{p i}$ & $V_{i}$ (tons) & $T_{i}^{\prime}(\sec )$ \\
\hline 1 & 2.4 & 0.58 & 0.29 & 1.82 & 0.58 & 75.1 & 2.61 \\
\hline 2 & 0.8 & 0.27 & 0.14 & 1.38 & 0.73 & 44.3 & 0.86 \\
\hline 3 & 0.43 & 0.09 & 0.04 & 1.12 & 0.93 & 25.6 & 0.45 \\
\hline 4 & 0.28 & 0.04 & 0.02 & 1.05 & 0.98 & 17.6 & 0.29 \\
\hline 5 & 0.21 & 0.01 & 0.01 & 1.02 & 0.99 & 8.1 & 0.22 \\
\hline 6 & 0.15 & 0.01 & 0.00 & 1.01 & 0.99 & 7.1 & 0.16 \\
\hline
\end{tabular}

Table 6: Calculation of the modal base shears for the building reentrant in plan (DI=0.5).

\begin{tabular}{|c|c|c|c|c|c|c|c|}
\hline Mode number & $T_{i}(\mathrm{sec})$ & $E \boldsymbol{R}_{i}$ & $D I_{i}$ & $\mu_{i}$ & $a_{p i}$ & $V_{i}$ (tons) & $T_{i}^{\prime}(\mathrm{sec})$ \\
\hline 1 & 2.24 & 0.58 & 0.29 & 1.82 & 0.63 & 81.0 & 2.38 \\
\hline 2 & 0.73 & 0.29 & 0.14 & 1.40 & 0.71 & 43.9 & 0.76 \\
\hline 3 & 0.38 & 0.08 & 0.04 & 1.11 & 0.94 & 26.6 & 0.39 \\
\hline 4 & 0.24 & 0.03 & 0.02 & 1.04 & 0.98 & 17.3 & 0.24 \\
\hline 5 & 0.17 & 0.01 & 0.01 & 1.01 & 0.99 & 8.1 & 0.17 \\
\hline 6 & 0.13 & 0.01 & 0.00 & 1.01 & 0.99 & 6.8 & 0.13 \\
\hline
\end{tabular}

Table 7: Calculation of the modal base shears for the building with irregularity in elevation (DI=0.5).

\begin{tabular}{|c|c|c|c|c|c|c|c|}
\hline Mode number & $T_{i}(\mathrm{sec})$ & $E R_{i}$ & $D I_{i}$ & $\mu_{i}$ & $a_{p i}$ & $V_{i}$ (tons) & $T_{i}^{\prime}(\mathrm{sec})$ \\
\hline 1 & 2.18 & 0.59 & 0.30 & 1.83 & 0.63 & 95.9 & 2.32 \\
\hline 2 & 0.79 & 0.30 & 0.15 & 1.42 & 0.70 & 55.3 & 0.83 \\
\hline 3 & 0.43 & 0.06 & 0.03 & 1.09 & 0.95 & 21.8 & 0.44 \\
\hline 4 & 0.27 & 0.02 & 0.01 & 1.03 & 0.99 & 13.5 & 0.28 \\
\hline 5 & 0.21 & 0.01 & 0.01 & 1.02 & 0.99 & 9.3 & 0.21 \\
\hline 6 & 0.16 & 0.01 & 0.00 & 1.01 & 1.00 & 8.7 & 0.16 \\
\hline
\end{tabular}

Table 8: Calculation of the modal base shears for the building with non-perpendicular systems (DI=0.5).

\begin{tabular}{|c|c|c|c|c|c|c|c|}
\hline Mode number & $T_{i}(\mathrm{sec})$ & $E \boldsymbol{R}_{i}$ & $D I_{i}$ & $\mu_{i}$ & $a_{p i}$ & $V_{i}$ (tons) & $T_{i}^{\prime}(\sec )$ \\
\hline 1 & 2.16 & 0.57 & 0.28 & 1.80 & 0.63 & 121 & 2.28 \\
\hline 2 & 0.72 & 0.29 & 0.14 & 1.40 & 0.72 & 68 & 0.74 \\
\hline 3 & 0.38 & 0.07 & 0.04 & 1.10 & 0.93 & 37 & 0.39 \\
\hline 4 & 0.24 & 0.03 & 0.02 & 1.04 & 0.98 & 25 & 0.24 \\
\hline 5 & 0.18 & 0.01 & 0.01 & 1.02 & 1.00 & 13 & 0.18 \\
\hline 6 & 0.13 & 0.01 & 0.00 & 1.01 & 1.00 & 12 & 0.13 \\
\hline
\end{tabular}

According to Tables 5-8 a large part of plastic action occurs in the lower modes, as expected. Figure 7 shows comparison of the modal base shears calculated by the proposed method and the code. The code-based base shear can be calculated using any desirable seismic code. But here it is simply determined using Eq. (15) without the coefficient $a_{p i}$ and by dividing it by the Rfactor that is equal to 5 as stated at the beginning of this section.

It is observed that for $\mathrm{DI}=0.5$, that is not necessarily consistent with the code, the first mode base shear is at most about $20 \%$ smaller and about $6 \%$ larger with the proposed method for the regular building and the one with non-perpendicular systems, respectively.

In order to compare the seismic behaviour of the designed buildings, a pushover analysis is performed. The target displacements are determined to be $44,40.8,44$ and $35.7 \mathrm{~cm}$ for the buildings of Tables 5-8, respectively, according to ASCE41-
13 [20]. Pushover analysis is sufficient for low and mid-rise buildings. As known, the pushover analysis is a strong and efficient method that can be used for seismic evaluation of buildings in that height range without concern. Figure 8 compares the pushover curves of the buildings.

Consistent with Figure 7, the pushover curves of Figure 8 show that for $\mathrm{DI}=0.5$, the lateral stiffness and strength of the buildings are somewhat inferior to the ones according to the code-based design.

Table 9 shows number of plastic hinges and their performance levels according to ASCE41-13 [20] at the target displacement in different cases. The plastic hinges are of the concentrated type at the ends of the members. Characteristics of the bending plastic hinges of the steel beams and bending-axial force interaction plastic hinges for the steel columns have been extracted from ASCE41-13 [20]. 


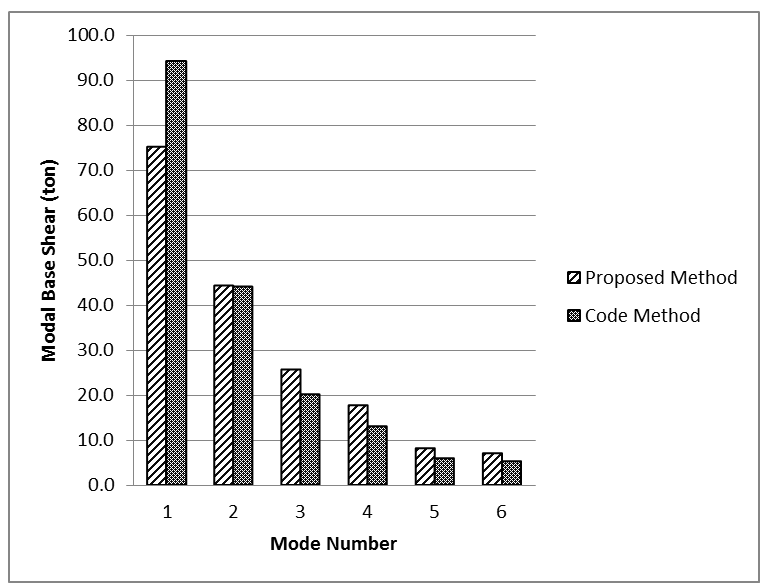

(a)

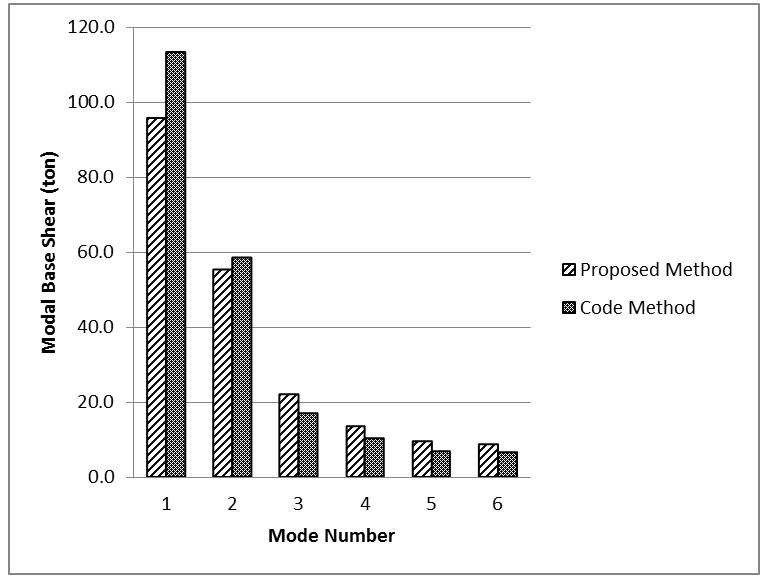

(c)

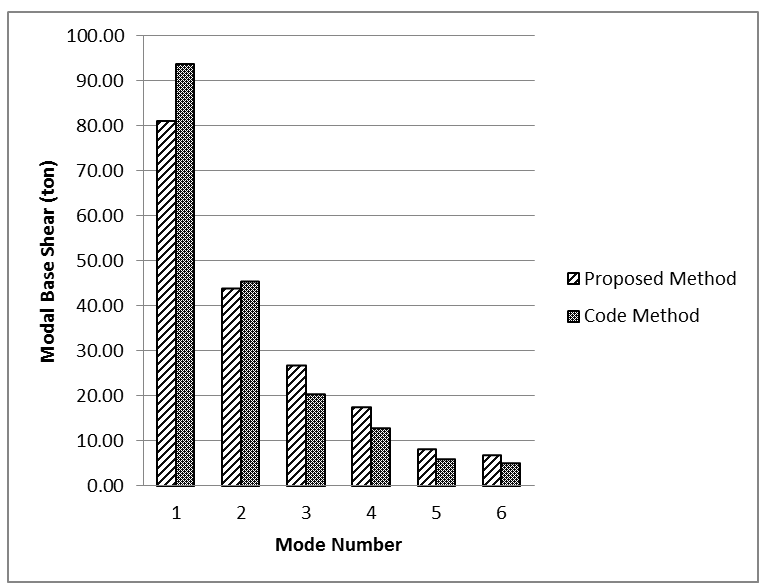

(b)

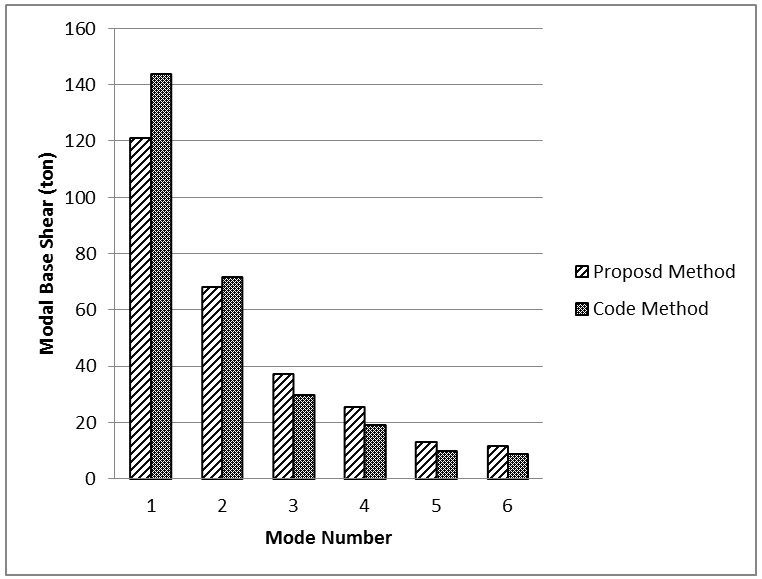

(d)

Figure 7: Comparison of the modal base shears, DI=0.5, for the buildings: (a) Regular; (b) With reentrance in plan; (c) With irregularity in elevation; (d) With non-perpendicular systems.

Table 9: Number of plastic hinges and their performance levels $(D I=0.5)$.

\begin{tabular}{|c|c|c|c|c|c|c|c|c|c|}
\hline \multirow{2}{*}{ Type of building } & \multirow{2}{*}{ Design method } & \multirow[b]{2}{*}{10} & \multicolumn{2}{|c|}{ Beams } & \multirow[b]{2}{*}{$>\mathrm{CP}$} & \multirow[b]{2}{*}{10} & \multicolumn{2}{|c|}{ Columns } & \multirow[b]{2}{*}{$>\mathrm{CF}$} \\
\hline & & & LS & $\mathrm{CP}$ & & & LS & $\mathrm{CP}$ & \\
\hline \multirow{2}{*}{ Regular } & Code based & 135 & 20 & - & - & 32 & - & - & - \\
\hline & Proposed & 134 & 32 & - & - & 13 & - & - & - \\
\hline \multirow{2}{*}{ Irregular in plan } & Code based & 142 & 23 & - & - & 10 & - & - & - \\
\hline & Proposed & 138 & 28 & - & - & 9 & - & - & - \\
\hline \multirow{2}{*}{ Irregular in height } & Code based & 142 & 3 & - & - & 43 & - & - & - \\
\hline & Proposed & 138 & 16 & - & - & 38 & - & - & - \\
\hline \multirow{2}{*}{ Non-perpendicular } & Code based & 165 & - & - & - & 10 & - & - & - \\
\hline & Proposed & 177 & 2 & - & - & 12 & - & - & - \\
\hline
\end{tabular}




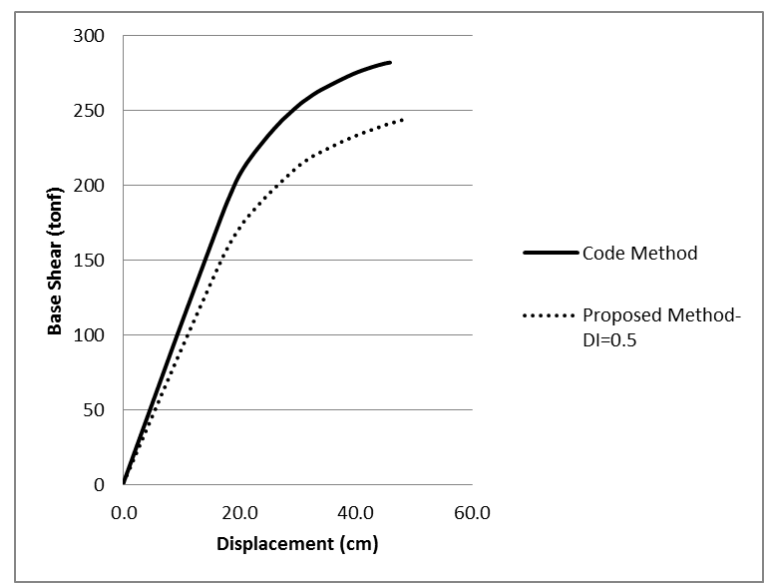

(a)

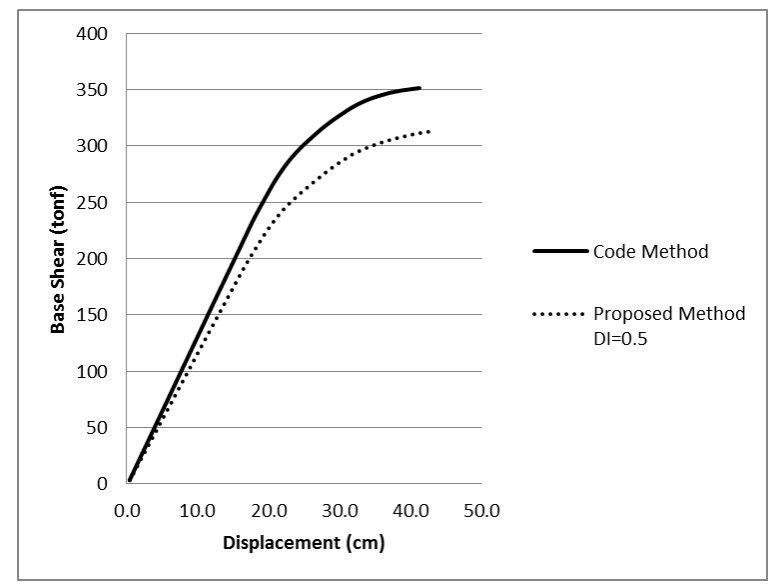

(c)

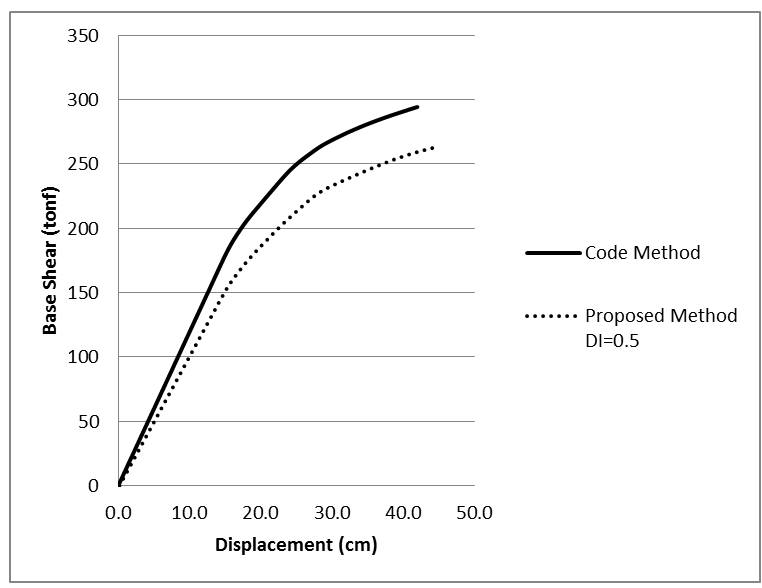

(b)

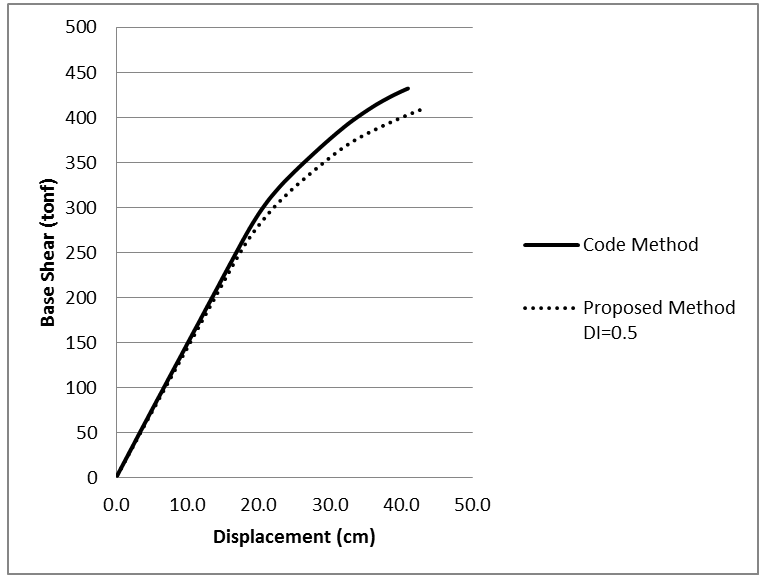

(d)

Figure 8: Pushover diagrams of the buildings. (a) The regular building. (b) Building reentrant in plan. (c) Building with irregularity in elevation. (d) Building with non-perpendicular systems.

Table 9 clearly shows that the current method is successful in providing a safe behaviour for special steel moment frames at life safety under the design hazard level.

In Appendix A, results of analysis with the proposed method are shown also for $\mathrm{DI}=0.3$ and $\mathrm{DI}=0.7$ that correspond to smaller and larger extents of seismic damage, respectively. It is meant to show that how the method can be used for desirable values of the damage index.

\section{CONCLUSIONS}

In this paper a new method was presented for spectral analysis and design of structures based on ductility demand. For this purpose, inelastic acceleration response spectra were calculated for more than 27,000 combinations of PGA, ductility factor, and period. Then a method for calculation of design PGA and a procedure for determining the modal ductility demands for different modes were presented. Practical application of the proposed method was explained through solving several examples. Nonlinear static evaluation of the buildings designed according to the proposed method displayed that the level of structural damage is straightforwardly controllable with the suggested method contrary to the code-based conventional design. Implementation of the proposed method only needs $T_{i}$ (from eigen-value analysis), $E R_{i}$ (from Eqs. 9 and 10), $D I_{i}$ (from Eq. 11), $\mu_{i}$ (from Eq. 14), and $a_{p i}$ (from Figure 3 or Table
A.11) to calculate $V_{i}$ (the modal base shear). On top of that, it is not an iterational procedure since the design base shear is dependent on the values of the ductility factor and the damage index selected by designer in the first place. This bears less calculations than the usual spectral analysis that needs to be repeated until the allowable story drifts are satisfied.

\section{REFERENCES}

1 Bertero RD and Bertero VV (2000). "Application of a comprehensive approach for the performance based earthquake resistant design buildings". 12th World Conference on Earthquake Engineering, Auckland, NZ.

2 Park YJ and Ang AH (1985). "Mechanistic seismic damage model for reinforced concrete". Journal of Structural Engineering, 111(4): 722-739.

3 Medhekar MS and Kennedy DJ (2000). "Displacementbased seismic design of buildings - theory". Engineering Structures, 22(3): 201-209.

4 Borzi B, Calvi GM, Elnashai AS, Faccioli E and Bommer JJ (2001). "Inelastic spectra for displacement-based seismic design". Soil Dynamics and Earthquake Engineering, 21(1): 47-61.

5 Chopra AK and Goel RK (2001). "Direct displacementbased design: use of inelastic vs. elastic design spectra". Earthquake Spectra, 17(1): 47-64. 
6 Kim J and Seo Y (2004). "Seismic design of low-rise steel frames with buckling-restrained braces". Engineering structures, 26(5): 543-551.

7 Christopoulos C and Pampanin S (2004). "Towards performance-based design of MDOF structures with explicit consideration of residual deformations". ISET Journal of Earthquake Technology, 41(1): 53-73.

8 Choi H and Kim J (2006). "Energy-based seismic design of buckling-restrained braced frames using hysteretic energy spectrum”. Engineering Structures, 28(2): 304-311.

9 Priestley MJ, Calvi GM and Kowalsky MJ (2007). "Direct displacement-based seismic design of structures". New Zealand Society for Earthquake Engineering Annual Conference, Palmerston North, NZ.

10 Sahoo DR and Chao SH (2010). "Performance-based plastic design method for buckling-restrained braced frames ”. Engineering Structures, 32(9): 2950-2958.

11 Grigorian M and Grigorian C (2011). "Performance control for seismic design of moment frames". Journal of Constructional Steel Research, 67(7): 1106-1114.

12 Wongpakdee N, Leelataviwat S, Goel SC and Liao WC (2014). "Performance-based design and collapse evaluation of buckling restrained knee braced truss moment frames". Engineering Structures, 60: 23-31.

13 Banihashemi MR, Mirzagoltabar AR and Tavakoli HR (2015). "Development of the performance based plastic design for steel moment resistant frame". International Journal of Steel Structures, 15(1): 51-62.
14 Vamvatsikos D and Aschheim M (2014). "Direct performance-based seismic design of structures using yield frequency spectra”. The $10^{\text {th }}$ U.S. National Conference on Earthquake Engineering, Anchorage, AL.

15 NZS1170.5 (2004). "Structural Design Actions Part 5: Earthquake Actions". Standards New Zealand, Wellington, NZ.

16 FEMA P-750 (2009). "NEHRP Recommended Seismic Provisions for New Buildings and Other Structures". Federal Emergency Management Agency, Washington, DC.

17 PEER (2019). "Peer Ground Motion Database". Pacific Earthquake Engineering Research (PEER) Centre, University of California, Berkeley, CA. URL: http://peer.berkeley.edu.

18 OpenSees (2019). "Open System for Earthquake Engineering Simulation (OpenSees), Version 2.3.0". University of California, Berkeley, CA. Available from: http://opensees.berkeley.edu.

19 Cosenza E, Manfredi G and Ramasco R (1993). "The use of damage functionals in earthquake engineering: a comparison between different methods". Earthquake Engineering and Structural Dynamics, 22(10): 855-68.

20 ASCE 41-13 (2013). "Seismic Evaluation and Retrofit of Existing Buildings". American Society of Civil Engineers, Reston, Virginia.

\section{APPENDIX A. DESIGN RESULTS OF THE EXAMPLE BUILDING OF SEC. 6 FOR DI=0.3 AND DI=0.7.}

Table A.1: Calculation of the modal base shears for the regular building (DI=0.3).

\begin{tabular}{ccccccc} 
Mode number & $\begin{array}{c}\boldsymbol{T}_{\boldsymbol{i}} \\
(\mathbf{s e c})\end{array}$ & $\boldsymbol{E} \boldsymbol{R}_{\boldsymbol{i}}$ & $\boldsymbol{D I} \boldsymbol{I}_{\boldsymbol{i}}$ & $\boldsymbol{\mu}_{\boldsymbol{i}}$ & $\boldsymbol{a}_{\boldsymbol{p} \boldsymbol{i}}$ & $\boldsymbol{V}_{\boldsymbol{i}}$ (tons) \\
\hline 1 & 2.4 & 0.58 & 0.18 & 1.49 & 0.73 & 99.6 \\
2 & 0.8 & 0.29 & 0.09 & 1.24 & 0.83 & 55.4 \\
3 & 0.43 & 0.08 & 0.02 & 1.07 & 0.96 & 28.9 \\
4 & 0.28 & 0.03 & 0.01 & 1.03 & 0.98 & 18.5 \\
5 & 0.21 & 0.01 & 0.00 & 1.01 & 1.00 & 8.6 \\
6 & 0.15 & 0.01 & 0.00 & 1.01 & 1.00 & 0.38 \\
\hline
\end{tabular}

Table A.2: Calculation of the modal base shears for the building reentrant in plan (DI=0.3).

\begin{tabular}{ccccccc} 
Mode number & $\begin{array}{c}\boldsymbol{T}_{\boldsymbol{i}} \\
(\mathbf{s e c})\end{array}$ & $\boldsymbol{E} \boldsymbol{R}_{\boldsymbol{i}}$ & $\boldsymbol{D} \boldsymbol{I}_{\boldsymbol{i}}$ & $\boldsymbol{\mu}_{\boldsymbol{i}}$ & $\boldsymbol{a}_{\boldsymbol{p} \boldsymbol{i}}$ & $\boldsymbol{V}_{\boldsymbol{i}}$ (tons) \\
\hline 1 & 2.24 & 0.58 & 0.17 & 1.48 & 0.77 & 100.5 \\
2 & 0.73 & 0.30 & 0.09 & 1.25 & 0.82 & 53.9 \\
3 & 0.38 & 0.08 & 0.02 & 1.07 & 0.96 & 28.1 \\
4 & 0.24 & 0.03 & 0.01 & 1.03 & 0.99 & 18.4 \\
5 & 0.17 & 0.01 & 0.00 & 1.01 & 1.00 & 9.3 \\
6 & 0.13 & 0.01 & 0.00 & 1.01 & 1.00 & 0.37 \\
\hline
\end{tabular}

Table A.3: Calculation of the modal base shears for the building with irregularity in elevation (DI=0.3).

\begin{tabular}{ccccccc} 
Mode number & $\begin{array}{c}\boldsymbol{T}_{\boldsymbol{i}} \\
(\mathbf{s e c})\end{array}$ & $\boldsymbol{E} \boldsymbol{R}_{\boldsymbol{i}}$ & $\boldsymbol{D} \boldsymbol{I}_{\boldsymbol{i}}$ & $\boldsymbol{\mu}_{\boldsymbol{i}}$ & $\boldsymbol{a}_{\boldsymbol{p} \boldsymbol{i}}$ & $\boldsymbol{V}_{\boldsymbol{i}}$ (tons) \\
\hline 1 & 2.18 & 0.58 & 0.17 & 1.49 & 0.76 & 122.8 \\
2 & 0.79 & 0.32 & 0.10 & 1.27 & 0.81 & 70.6 \\
3 & 0.43 & 0.06 & 0.02 & 1.05 & 0.97 & 24.9 \\
4 & 0.27 & 0.02 & 0.01 & 1.02 & 0.99 & 14.3 \\
5 & 0.21 & 0.01 & 0.00 & 1.01 & 1.00 & 10.1 \\
6 & 0.16 & 0.01 & 0.00 & 1.01 & 1.00 & 0.38 \\
\hline
\end{tabular}


Table A.4: Calculation of the modal base shears for the building with non-perpendicular systems (DI=0.3).

\begin{tabular}{|c|c|c|c|c|c|c|c|}
\hline Mode number & $\begin{array}{c}T_{i} \\
(\mathrm{sec})\end{array}$ & $E R_{i}$ & $D I_{i}$ & $\mu_{i}$ & $a_{p i}$ & $V_{i}$ (tons) & $T^{\prime}{ }_{i}(\mathrm{sec})$ \\
\hline 1 & 2.16 & 0.57 & 0.17 & 1.48 & 0.71 & 136.3 & 1.98 \\
\hline 2 & 0.72 & 0.29 & 0.09 & 1.24 & 0.83 & 78.3 & 0.64 \\
\hline 3 & 0.38 & 0.07 & 0.02 & 1.06 & 0.96 & 38.2 & 0.33 \\
\hline 4 & 0.24 & 0.03 & 0.01 & 1.03 & 0.99 & 25.5 & 0.21 \\
\hline 5 & 0.18 & 0.01 & 0.00 & 1.01 & 1.00 & 13.1 & 0.14 \\
\hline 6 & 0.13 & 0.01 & 0.00 & 1.01 & 1.00 & 11.5 & 0.11 \\
\hline
\end{tabular}

Table A.5: Calculation of the modal base shears for the regular building (DI=0.7).

\begin{tabular}{ccccccc} 
Mode number & $\begin{array}{c}\boldsymbol{T}_{\boldsymbol{i}} \\
(\mathbf{s e c})\end{array}$ & $\boldsymbol{E} \boldsymbol{R}_{\boldsymbol{i}}$ & $\boldsymbol{D} \boldsymbol{I}_{\boldsymbol{i}}$ & $\boldsymbol{\mu}_{\boldsymbol{i}}$ & $\boldsymbol{a}_{\boldsymbol{p} \boldsymbol{i}}$ & $\boldsymbol{V}_{\boldsymbol{i}}$ (tons) \\
\hline 1 & 2.4 & 0.58 & 0.41 & 2.14 & 0.50 & 64.6 \\
2 & 0.8 & 0.27 & 0.19 & 1.53 & 0.64 & 38.8 \\
3 & 0.43 & 0.09 & 0.06 & 1.17 & 0.90 & 24.8 \\
4 & 0.28 & 0.04 & 0.03 & 1.07 & 0.97 & 17.4 \\
5 & 0.21 & 0.01 & 0.01 & 1.02 & 1.00 & 0.91 \\
6 & 0.15 & 0.01 & 0.01 & 1.02 & 1.00 & 0.31 \\
\hline
\end{tabular}

Table A.6: Calculation of the modal base shears for the building with reentrance in plan (DI=0.7).

\begin{tabular}{ccccccc} 
Mode number & $\begin{array}{c}\boldsymbol{T}_{\boldsymbol{i}} \\
(\mathbf{s e c})\end{array}$ & $\boldsymbol{E} \boldsymbol{R}_{\boldsymbol{i}}$ & $\boldsymbol{D I}_{\boldsymbol{i}}$ & $\boldsymbol{\mu}_{\boldsymbol{i}}$ & $\boldsymbol{a}_{\boldsymbol{p} \boldsymbol{i}}$ & $\boldsymbol{V}_{\boldsymbol{i}}$ (tons) \\
\hline 1 & 2.24 & 0.58 & 0.41 & 2.15 & 0.53 & 68.18 \\
2 & 0.73 & 0.29 & 0.20 & 1.56 & 0.62 & 38.57 \\
3 & 0.38 & 0.08 & 0.06 & 1.16 & 0.91 & 25.80 \\
4 & 0.24 & 0.03 & 0.02 & 1.06 & 0.97 & 17.14 \\
5 & 0.17 & 0.01 & 0.01 & 1.02 & 1.00 & 8.15 \\
6 & 0.13 & 0.01 & 0.00 & 1.01 & 1.00 & 0.86 \\
\hline
\end{tabular}

Table A.7: Calculation of the modal base shears for the building with irregularity in elevation (DI=0.7).

\begin{tabular}{ccccccc} 
Mode number & $\begin{array}{c}\boldsymbol{T}_{\boldsymbol{i}} \\
(\mathbf{s e c})\end{array}$ & $\boldsymbol{E} \boldsymbol{R}_{\boldsymbol{i}}$ & $\boldsymbol{D I}_{\boldsymbol{i}}$ & $\boldsymbol{\mu}_{\boldsymbol{i}}$ & $\boldsymbol{a}_{\boldsymbol{p} \boldsymbol{i}}$ & $\boldsymbol{V}_{\boldsymbol{i}}$ (tons) \\
\hline 1 & 2.18 & 0.59 & 0.41 & 2.16 & 0.52 & 78.6 \\
2 & 0.79 & 0.30 & 0.21 & 1.59 & 0.61 & 48.2 \\
3 & 0.43 & 0.06 & 0.04 & 1.12 & 0.93 & 21.4 \\
4 & 0.27 & 0.02 & 0.02 & 1.05 & 0.98 & 13.4 \\
5 & 0.21 & 0.01 & 0.01 & 1.02 & 1.00 & 9.3 \\
6 & 0.16 & 0.01 & 0.01 & 1.02 & 1.00 & 0.30 \\
\hline
\end{tabular}

Table A.8: Calculation of the modal base shears for the building with non-perpendicular systems (DI=0.7).

\begin{tabular}{cccccccc} 
Mode number & $\begin{array}{c}\boldsymbol{T}_{\boldsymbol{i}} \\
(\mathbf{s e c})\end{array}$ & $\boldsymbol{E R}_{\boldsymbol{i}}$ & $\boldsymbol{D I}_{\boldsymbol{i}}$ & $\boldsymbol{\mu}_{\boldsymbol{i}}$ & $\boldsymbol{a}_{\boldsymbol{p} \boldsymbol{i}}$ & $\boldsymbol{V}_{\boldsymbol{i}}$ (tons) & $\boldsymbol{T}^{\prime}{ }_{\boldsymbol{i}}$ (sec) \\
\hline 1 & 2.16 & 0.57 & 0.40 & 2.12 & 0.54 & 104 & 2.51 \\
2 & 0.72 & 0.29 & 0.20 & 1.56 & 0.63 & 59 & 0.79 \\
3 & 0.38 & 0.07 & 0.05 & 1.14 & 0.90 & 36 & 0.41 \\
4 & 0.24 & 0.03 & 0.02 & 1.06 & 0.97 & 25 & 0.25 \\
5 & 0.18 & 0.01 & 0.01 & 1.02 & 1.00 & 13 & 0.18 \\
6 & 0.13 & 0.01 & 0.00 & 1.01 & 1.00 & 12 & 0.13 \\
\hline
\end{tabular}




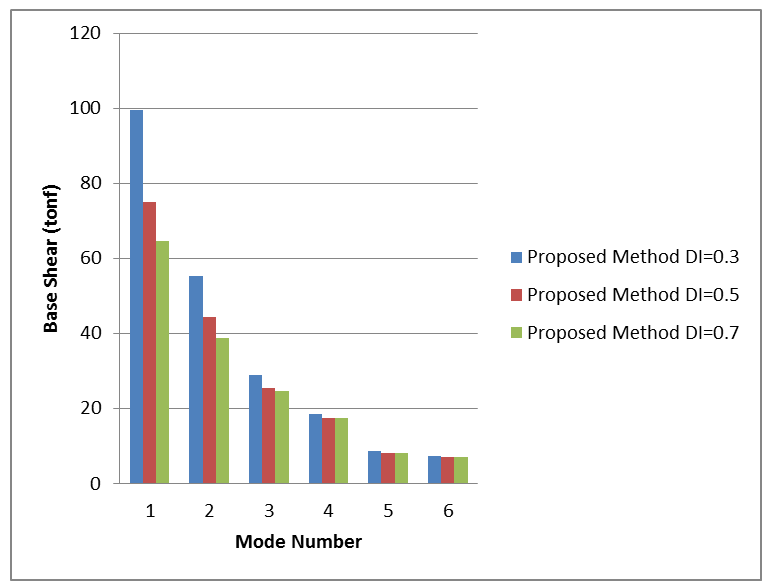

(a)

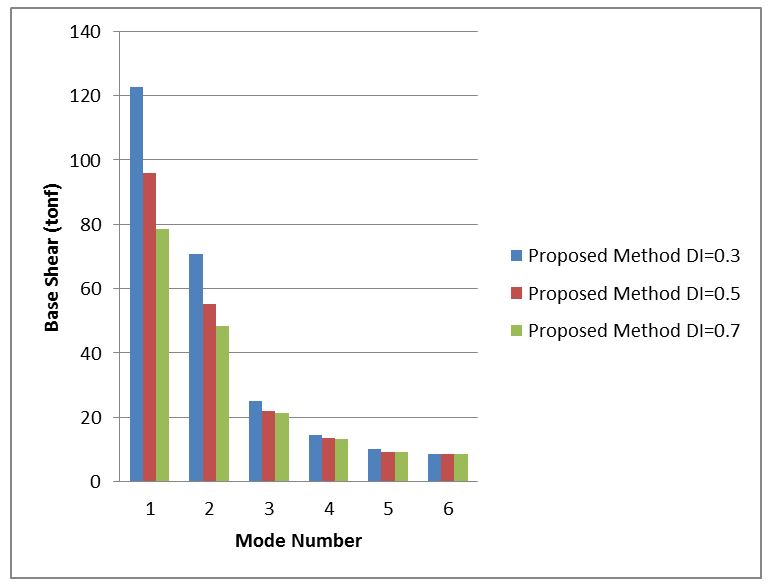

(c)

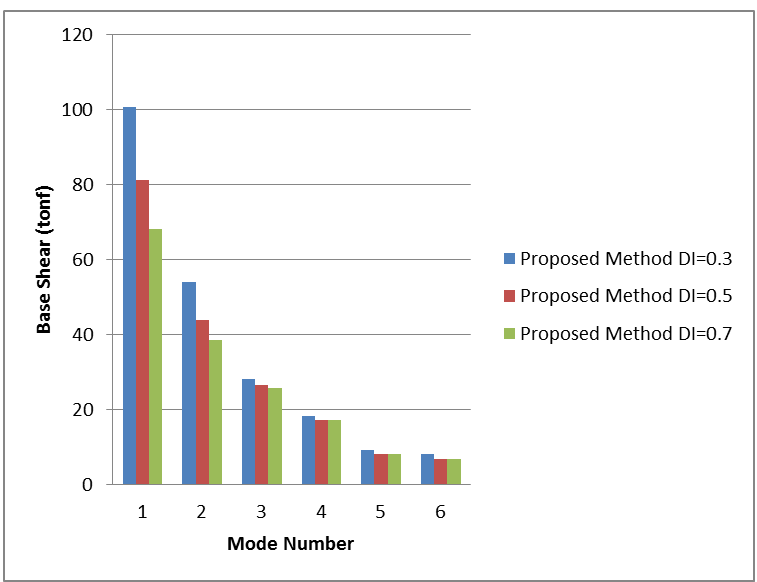

(b)

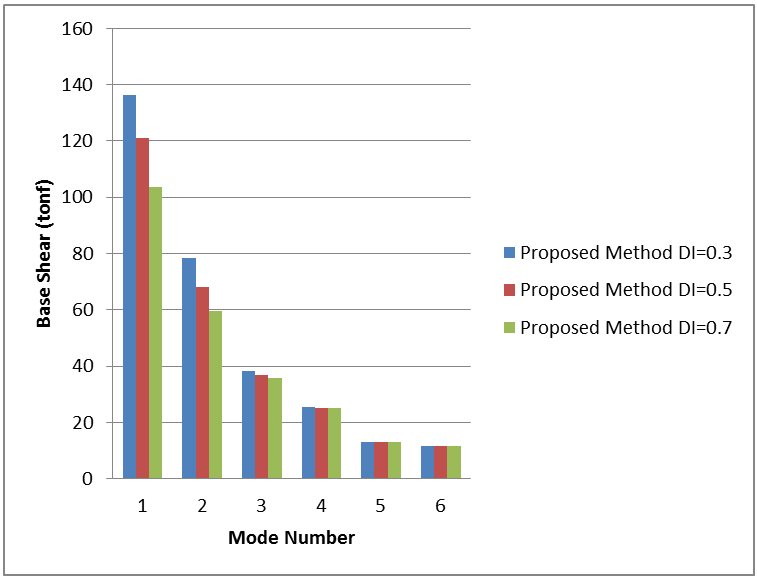

(d)

Figure A.1: Comparison of the modal base shears for the buildings: (a) Regular; (b) with reentrance in plan; (c) with irregularity in elevation; (d) with non-perpendicular systems.

Table A.9: Number of plastic hinges and performance levels for buildings of the proposed method, DI=0.3.

\begin{tabular}{|c|c|c|c|c|c|c|c|c|}
\hline \multirow{2}{*}{ Type of building } & \multirow[b]{2}{*}{10} & \multicolumn{2}{|c|}{ Beams } & \multirow[b]{2}{*}{$>C P$} & \multirow[b]{2}{*}{10} & \multicolumn{2}{|c|}{ Columns } & \multirow[b]{2}{*}{$>\mathrm{CP}$} \\
\hline & & LS & $\mathbf{C P}$ & & & LS & $\mathbf{C P}$ & \\
\hline Regular & 148 & 24 & - & - & 9 & - & - & - \\
\hline Irregular in plan & 149 & 18 & - & - & 4 & - & - & - \\
\hline Irregular in height & 160 & - & - & - & 13 & - & - & - \\
\hline Non-perpendicular & 172 & - & - & - & 5 & - & - & - \\
\hline
\end{tabular}




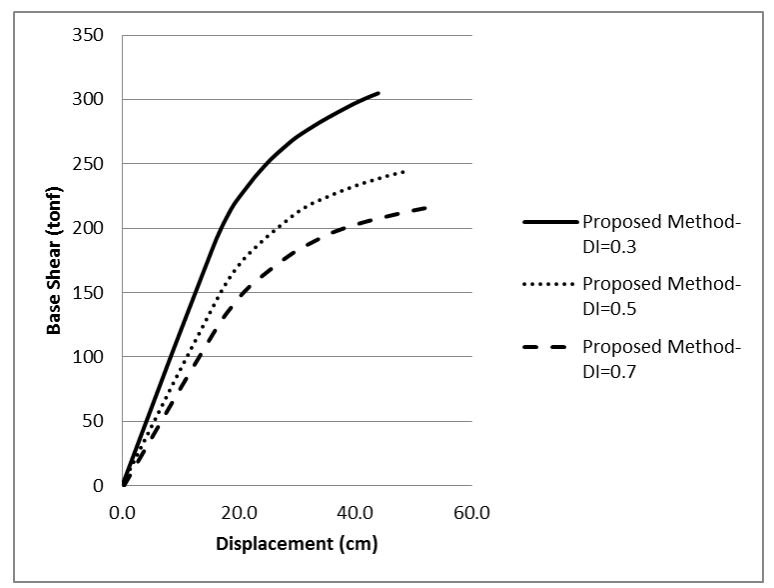

(a)

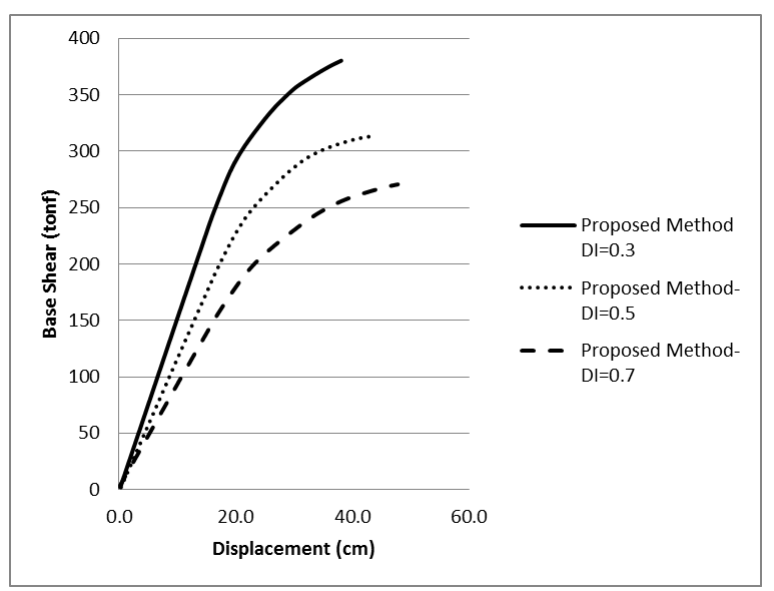

(c)

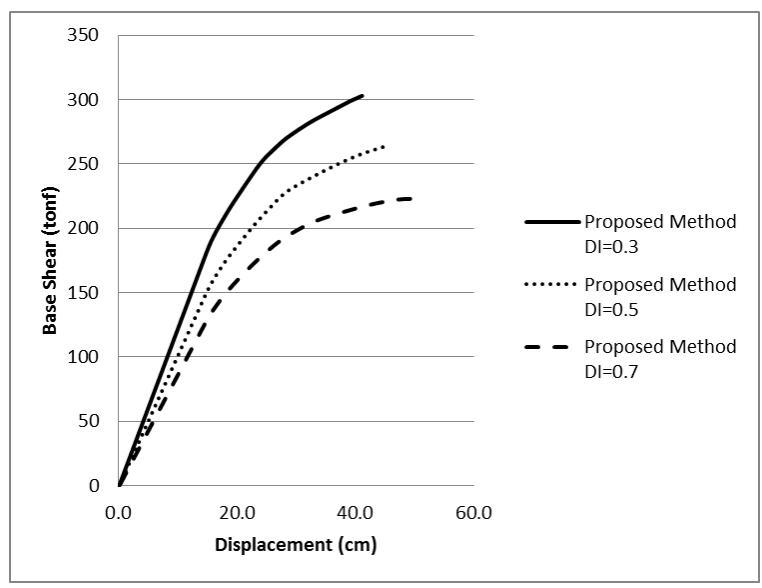

(b)

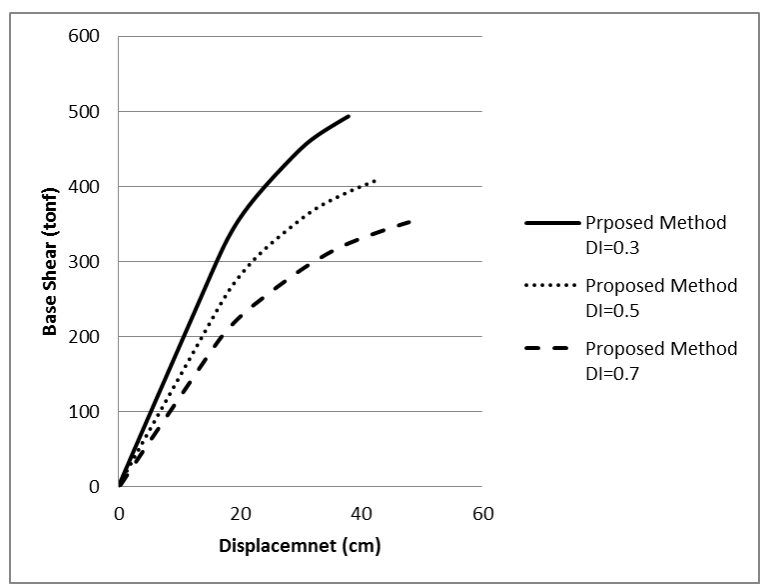

(d)

Figure A.2: Pushover diagrams of the buildings: (a) The regular building; (b) Building reentrant in plan; (c) Building with irregularity in elevation; and (d) Building with non-perpendicular systems.

Table A.10: Number of plastic hinges and performance levels for buildings of the proposed method, DI=0.7.

\begin{tabular}{|c|c|c|c|c|c|c|c|c|}
\hline \multirow{2}{*}{ Type of building } & \multirow[b]{2}{*}{10} & \multicolumn{2}{|c|}{ Beams } & \multirow[b]{2}{*}{$>\mathrm{CP}$} & \multirow[b]{2}{*}{10} & \multicolumn{2}{|c|}{ Columns } & \multirow[b]{2}{*}{$>\mathrm{CP}$} \\
\hline & & LS & $\mathbf{C P}$ & & & LS & $\mathbf{C P}$ & \\
\hline Regular & 111 & 40 & - & - & 22 & - & - & - \\
\hline Irregular in plan & 134 & 31 & - & - & 33 & - & - & - \\
\hline Irregular in height & 137 & 17 & - & - & 35 & - & - & - \\
\hline Non-perpendicular & 173 & 12 & - & - & 11 & - & - & - \\
\hline
\end{tabular}




\section{Table A.11: Values of $a_{p}$}

Average of (ap), $\mu=3.0$

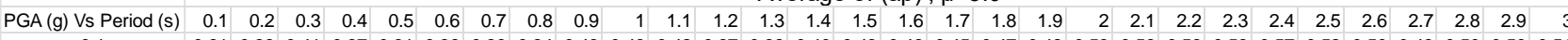
$\begin{array}{llllllllllllllllllllllllllllllll}0.1 & 0.61 & 0.38 & 0.41 & 0.37 & 0.31 & 0.36 & 0.30 & 0.34 & 0.43 & 0.43 & 0.42 & 0.37 & 0.38 & 0.40 & 0.43 & 0.46 & 0.45 & 0.47 & 0.48 & 0.53 & 0.56 & 0.56 & 0.58 & 0.57 & 0.52 & 0.50 & 0.49 & 0.50 & 0.50 & 0.51\end{array}$

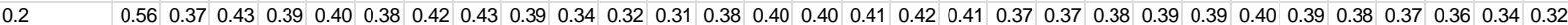
$\begin{array}{lllllllllllllllllllllllllllllllll}0.3 & 0.62 & 0.44 & 0.42 & 0.42 & 0.37 & 0.38 & 0.36 & 0.42 & 0.40 & 0.36 & 0.34 & 0.34 & 0.35 & 0.41 & 0.42 & 0.44 & 0.43 & 0.45 & 0.46 & 0.48 & 0.48 & 0.40 & 0.38 & 0.37 & 0.36 & 0.35 & 0.35 & 0.35 & 0.32 & 0.32\end{array}$ \begin{tabular}{l|l|l|l|l|l|l|l|l|l|l|l|l|l|l|l|l|l|l|l|l|l|l|l|l|l|l|l|l|l|l|l|l|l|l|l}
0.4 & 0.61 & 0.46 & 0.44 & 0.31 & 0.38 & 0.42 & 0.48 & 0.42 & 0.46 & 0.38 & 0.40 & 0.41 & 0.42 & 0.44 & 0.45 & 0.47 & 0.49 & 0.48 & 0.48 & 0.43 & 0.42 & 0.37 & 0.37 & 0.37 & 0.35 & 0.35 & 0.34 & 0.33 & 0.30 & 0.30
\end{tabular}

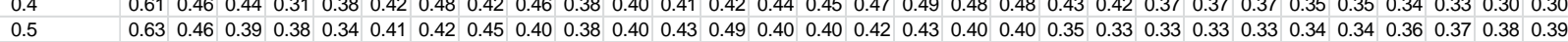
$\begin{array}{llllllllllllllllllllllllllllllllll}0.5 & 0.63 & 0.46 & 0.39 & 0.38 & 0.34 & 0.41 & 0.42 & 0.45 & 0.40 & 0.38 & 0.40 & 0.43 & 0.49 & 0.40 & 0.40 & 0.42 & 0.43 & 0.40 & 0.40 & 0.35 & 0.33 & 0.33 & 0.33 & 0.33 & 0.34 & 0.34 & 0.36 & 0.37 & 0.38 & 0.39 \\ 0.6 & 0.58 & 0.51 & 0.39 & 0.41 & 0.35 & 0.41 & 0.35 & 0.34 & 0.40 & 0.45 & 0.33 & 0.37 & 0.41 & 0.42 & 0.40 & 0.42 & 0.45 & 0.44 & 0.40 & 0.40 & 0.38 & 0.38 & 0.38 & 0.39 & 0.40 & 0.41 & 0.41 & 0.43 & 0.44 & 0.40\end{array}$

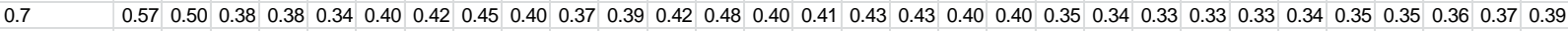
$\begin{array}{lllllllllllllllllllllllllllllllll}0.8 & 0.58 & 0.53 & 0.49 & 0.48 & 0.45 & 0.43 & 0.40 & 0.33 & 0.35 & 0.39 & 0.32 & 0.33 & 0.35 & 0.35 & 0.35 & 0.36 & 0.39 & 0.42 & 0.40 & 0.40 & 0.36 & 0.37 & 0.39 & 0.40 & 0.42 & 0.44 & 0.44 & 0.44 & 0.45 & 0.42\end{array}$ $\begin{array}{llllllllllllllllllllllllllllllllllll}0.9 & 0.56 & 0.50 & 0.42 & 0.44 & 0.40 & 0.43 & 0.44 & 0.39 & 0.38 & 0.36 & 0.33 & 0.36 & 0.40 & 0.44 & 0.40 & 0.38 & 0.40 & 0.42 & 0.42 & 0.44 & 0.43 & 0.39 & 0.38 & 0.38 & 0.38 & 0.39 & 0.38 & 0.38 & 0.39 & 0.36\end{array}$

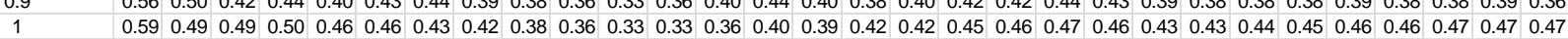

Average of (ap),$\mu=3.5$

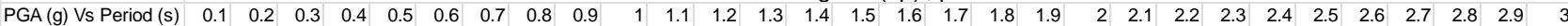

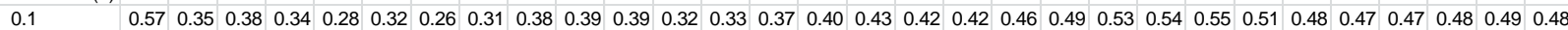

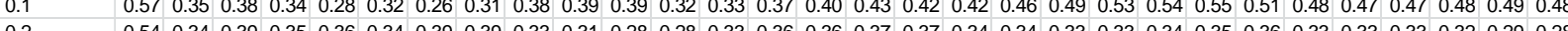

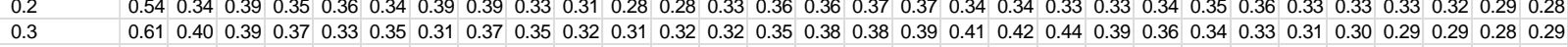

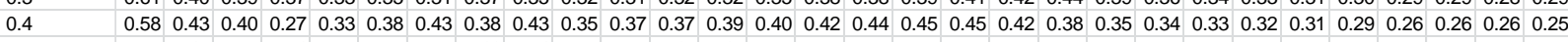

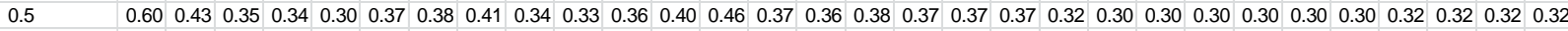
$\begin{array}{llllllllllllllllllllllllllllllllll}0.6 & 0.55 & 0.48 & 0.35 & 0.36 & 0.32 & 0.37 & 0.31 & 0.31 & 0.33 & 0.37 & 0.31 & 0.35 & 0.38 & 0.37 & 0.34 & 0.38 & 0.40 & 0.36 & 0.37 & 0.36 & 0.35 & 0.34 & 0.34 & 0.35 & 0.35 & 0.36 & 0.35 & 0.33 & 0.34 & 0.36\end{array}$ $\begin{array}{lllllllllllllllllllllllllllllllll}0.7 & 0.54 & 0.48 & 0.34 & 0.35 & 0.31 & 0.36 & 0.38 & 0.41 & 0.32 & 0.33 & 0.35 & 0.39 & 0.44 & 0.37 & 0.37 & 0.38 & 0.37 & 0.37 & 0.37 & 0.33 & 0.31 & 0.30 & 0.30 & 0.30 & 0.30 & 0.30 & 0.31 & 0.32 & 0.32 & 0.32\end{array}$ $\begin{array}{llllllllllllllllllllllllllllllll}0.8 & 0.56 & 0.50 & 0.46 & 0.43 & 0.42 & 0.40 & 0.34 & 0.30 & 0.29 & 0.33 & 0.28 & 0.30 & 0.32 & 0.30 & 0.30 & 0.32 & 0.33 & 0.32 & 0.35 & 0.33 & 0.33 & 0.33 & 0.34 & 0.35 & 0.36 & 0.38 & 0.37 & 0.35 & 0.36 & 0.39\end{array}$

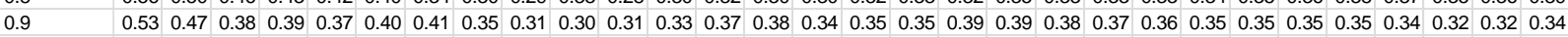

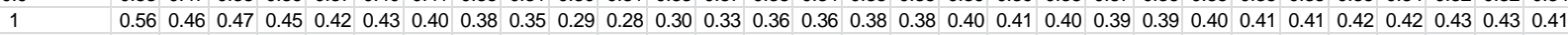

Average of (ap),$\mu=4.0$

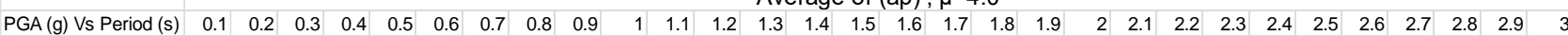

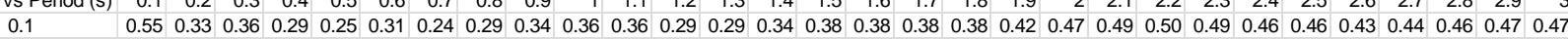

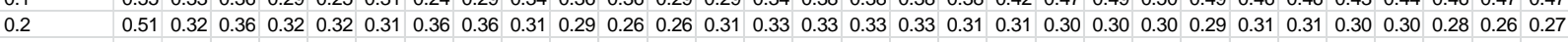
$\begin{array}{lllllllllllllllllllllllllllllll}0.3 & 0.59 & 0.38 & 0.36 & 0.33 & 0.31 & 0.32 & 0.28 & 0.34 & 0.33 & 0.30 & 0.29 & 0.29 & 0.29 & 0.32 & 0.35 & 0.35 & 0.36 & 0.36 & 0.39 & 0.38 & 0.35 & 0.33 & 0.31 & 0.30 & 0.28 & 0.25 & 0.25 & 0.26 & 0.25 & 0.26\end{array}$

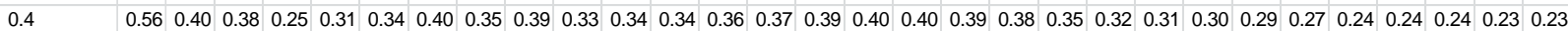
$\begin{array}{lllllllllllllllllllllllllllllll}0.5 & 0.58 & 0.41 & 0.33 & 0.32 & 0.27 & 0.34 & 0.36 & 0.34 & 0.31 & 0.31 & 0.34 & 0.38 & 0.37 & 0.35 & 0.33 & 0.34 & 0.32 & 0.34 & 0.33 & 0.29 & 0.28 & 0.27 & 0.28 & 0.28 & 0.27 & 0.28 & 0.29 & 0.29 & 0.28 & 0.28\end{array}$

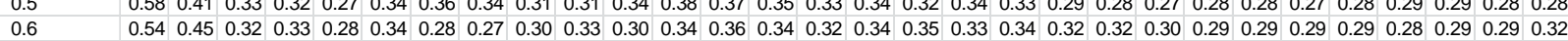

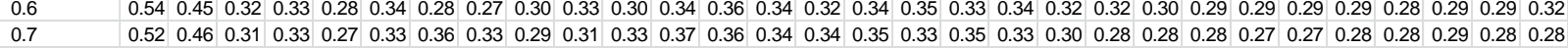

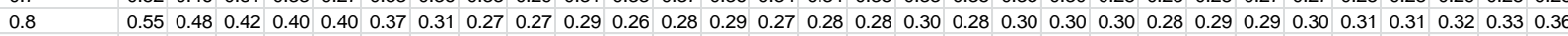
$\begin{array}{lllllllllllllllllllllllllllllllll}0.9 & 0.50 & 0.45 & 0.36 & 0.36 & 0.35 & 0.38 & 0.35 & 0.31 & 0.28 & 0.27 & 0.29 & 0.31 & 0.35 & 0.30 & 0.31 & 0.32 & 0.32 & 0.36 & 0.33 & 0.35 & 0.35 & 0.31 & 0.30 & 0.30 & 0.29 & 0.29 & 0.29 & 0.29 & 0.30 & 0.30\end{array}$

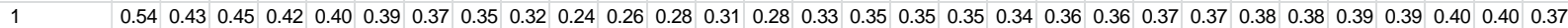

Average of (ap),$\mu=4.5$

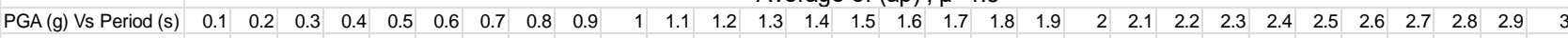

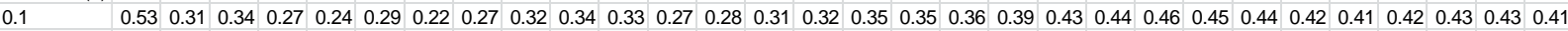

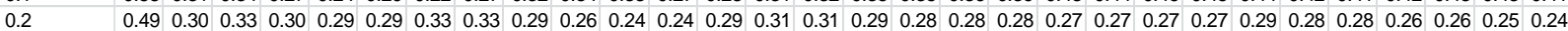
$\begin{array}{llllllllllllllllllllllllllllllll}0.3 & 0.58 & 0.36 & 0.35 & 0.31 & 0.29 & 0.30 & 0.26 & 0.31 & 0.30 & 0.29 & 0.27 & 0.27 & 0.27 & 0.30 & 0.33 & 0.32 & 0.33 & 0.35 & 0.35 & 0.35 & 0.32 & 0.30 & 0.29 & 0.27 & 0.25 & 0.24 & 0.24 & 0.24 & 0.24 & 0.24\end{array}$

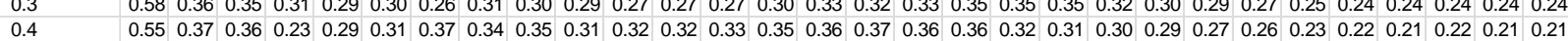

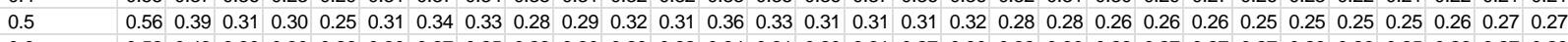
$\begin{array}{lllllllllllllllllllllllllllllll}0.6 & 0.52 & 0.43 & 0.30 & 0.30 & 0.26 & 0.30 & 0.27 & 0.25 & 0.28 & 0.30 & 0.29 & 0.32 & 0.34 & 0.31 & 0.30 & 0.31 & 0.27 & 0.30 & 0.32 & 0.30 & 0.28 & 0.27 & 0.27 & 0.27 & 0.26 & 0.26 & 0.25 & 0.26 & 0.27 & 0.29\end{array}$

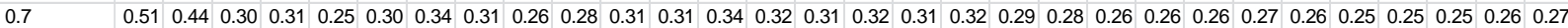

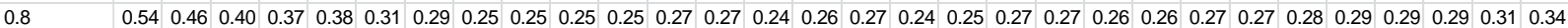

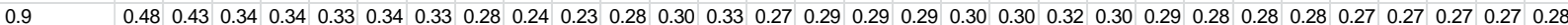

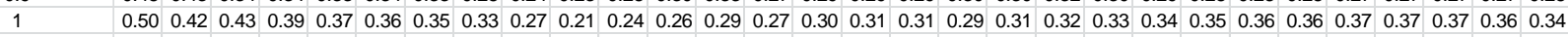

Average of (ap) $\mu=5.0$

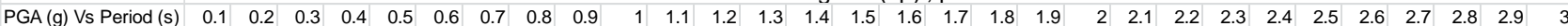

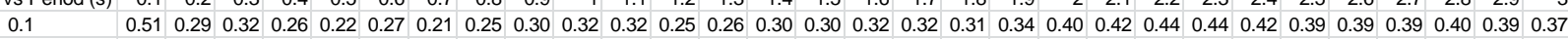

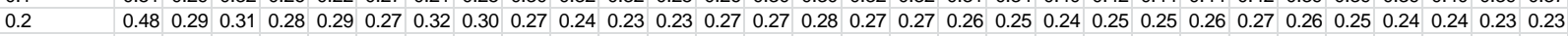

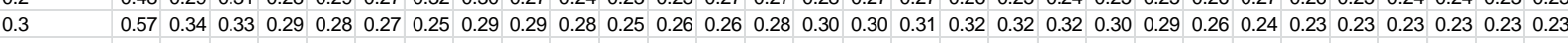
\begin{tabular}{l|llllllllllllllllllllllllllllll}
0.4 & 0.53 & 0.36 & 0.35 & 0.22 & 0.28 & 0.29 & 0.33 & 0.32 & 0.32 & 0.29 & 0.30 & 0.30 & 0.32 & 0.34 & 0.33 & 0.33 & 0.34 & 0.34 & 0.30 & 0.29 & 0.28 & 0.27 & 0.25 & 0.22 & 0.22 & 0.20 & 0.20 & 0.20 & 0.20 & 0.20
\end{tabular}

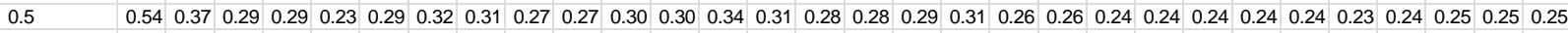

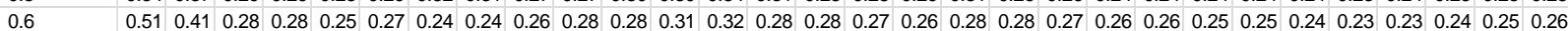

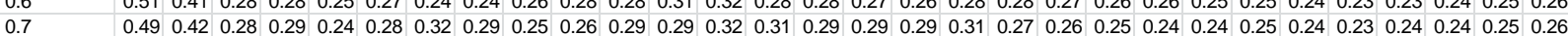

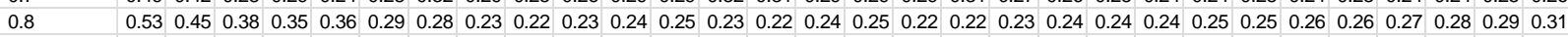

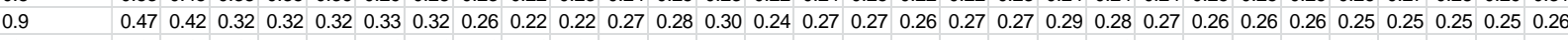

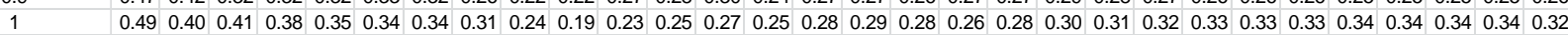

Average of (ap),$\mu=5.5$

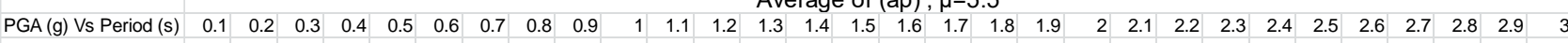
\begin{tabular}{l|lllllllllllllllllllllllllllllll}
0.1 & 0.50 & 0.28 & 0.31 & 0.24 & 0.21 & 0.25 & 0.20 & 0.24 & 0.28 & 0.30 & 0.29 & 0.24 & 0.26 & 0.28 & 0.29 & 0.31 & 0.30 & 0.30 & 0.34 & 0.38 & 0.42 & 0.41 & 0.42 & 0.39 & 0.38 & 0.35 & 0.36 & 0.36 & 0.37 & 0.36
\end{tabular} $\begin{array}{llllllllllllllllllllllllllllllll}0.2 & 0.46 & 0.28 & 0.28 & 0.26 & 0.27 & 0.26 & 0.30 & 0.29 & 0.25 & 0.23 & 0.21 & 0.22 & 0.25 & 0.26 & 0.26 & 0.25 & 0.25 & 0.24 & 0.22 & 0.22 & 0.23 & 0.24 & 0.24 & 0.25 & 0.24 & 0.23 & 0.23 & 0.23 & 0.22 & 0.22 & \end{array}$

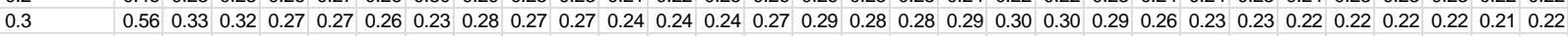
\begin{tabular}{l|lll|l|l|l|l|l|l|l|l|l|l|l|l|l|l|l|l|l|l|l|l|l|l|l|l|l|l|l}
0.4 & 0.52 & 0.34 & 0.33 & 0.21 & 0.26 & 0.28 & 0.32 & 0.31 & 0.30 & 0.28 & 0.29 & 0.29 & 0.30 & 0.31 & 0.31 & 0.32 & 0.32 & 0.29 & 0.28 & 0.27 & 0.26 & 0.24 & 0.21 & 0.21 & 0.20 & 0.20 & 0.20 & 0.19 & 0.19 & 0.19
\end{tabular}

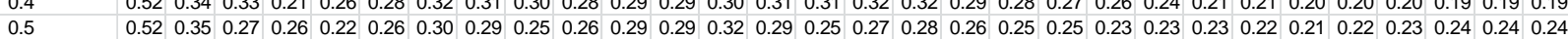

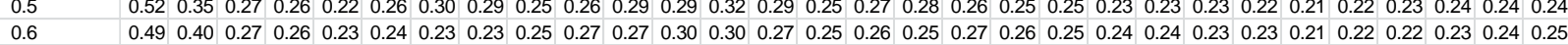

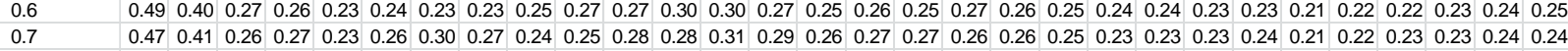
$\begin{array}{llllllllllllllllllllllllllllllll}0.8 & 0.51 & 0.43 & 0.36 & 0.34 & 0.34 & 0.28 & 0.26 & 0.21 & 0.21 & 0.22 & 0.23 & 0.24 & 0.21 & 0.21 & 0.23 & 0.24 & 0.21 & 0.21 & 0.22 & 0.22 & 0.22 & 0.23 & 0.23 & 0.24 & 0.24 & 0.25 & 0.25 & 0.26 & 0.27 & 0.29 & \end{array}$ $\begin{array}{llllllllllllllllllllllllllllllllll}0.9 & 0.45 & 0.40 & 0.30 & 0.30 & 0.31 & 0.31 & 0.29 & 0.23 & 0.20 & 0.20 & 0.25 & 0.27 & 0.24 & 0.23 & 0.25 & 0.26 & 0.23 & 0.26 & 0.25 & 0.27 & 0.26 & 0.25 & 0.25 & 0.25 & 0.24 & 0.24 & 0.23 & 0.24 & 0.24 & 0.24\end{array}$ $\begin{array}{llllllllllllllllllllllllllllllll}1 & 0.48 & 0.39 & 0.40 & 0.36 & 0.32 & 0.33 & 0.32 & 0.28 & 0.22 & 0.18 & 0.22 & 0.23 & 0.21 & 0.24 & 0.26 & 0.27 & 0.25 & 0.24 & 0.26 & 0.28 & 0.29 & 0.30 & 0.31 & 0.31 & 0.32 & 0.32 & 0.32 & 0.32 & 0.32 & 0.32\end{array}$

Average of (ap),$\mu=6.0$

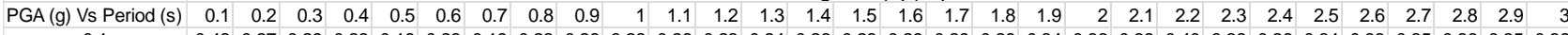

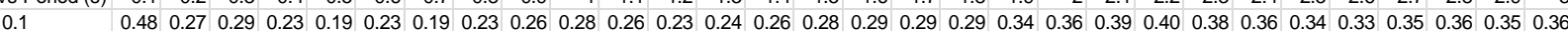

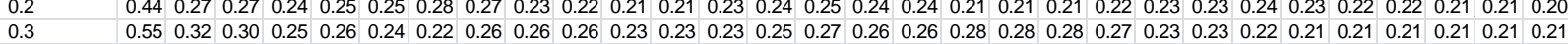
\begin{tabular}{l|lllllllllllllllllllllllllllllll}
0.3 & 0.55 & 0.32 & 0.30 & 0.25 & 0.26 & 0.24 & 0.22 & 0.26 & 0.26 & 0.26 & 0.23 & 0.23 & 0.23 & 0.25 & 0.27 & 0.26 & 0.26 & 0.28 & 0.28 & 0.28 & 0.27 & 0.23 & 0.23 & 0.22 & 0.21 & 0.21 & 0.21 & 0.21 & 0.21 & 0.21 \\
0.4 & 0.50 & 0.33 & 0.32 & 0.20 & 0.25 & 0.27 & 0.30 & 0.29 & 0.29 & 0.27 & 0.27 & 0.26 & 0.29 & 0.28 & 0.29 & 0.30 & 0.30 & 0.28 & 0.26 & 0.26 & 0.24 & 0.21 & 0.21 & 0.20 & 0.19 & 0.19 & 0.19 & 0.19 & 0.19 & 0.19
\end{tabular}

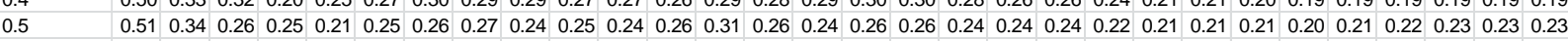
$\begin{array}{llllllllllllllllllllllllllllllllll}0.6 & & 0.48 & 0.38 & 0.26 & 0.25 & 0.22 & 0.23 & 0.22 & 0.22 & 0.23 & 0.26 & 0.26 & 0.28 & 0.28 & 0.24 & 0.24 & 0.25 & 0.24 & 0.25 & 0.25 & 0.24 & 0.23 & 0.22 & 0.21 & 0.22 & 0.20 & 0.20 & 0.21 & 0.22 & 0.23 & 0.24 & 0.25\end{array}$

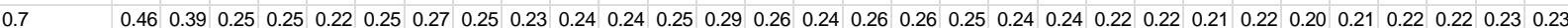

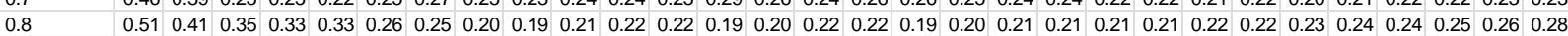
$\begin{array}{lllllllllllllllllllllllllllllll}0.9 & 0.45 & 0.38 & 0.30 & 0.29 & 0.30 & 0.27 & 0.28 & 0.21 & 0.18 & 0.19 & 0.24 & 0.26 & 0.22 & 0.21 & 0.23 & 0.23 & 0.22 & 0.24 & 0.24 & 0.25 & 0.25 & 0.24 & 0.23 & 0.23 & 0.23 & 0.22 & 0.22 & 0.22 & 0.22 & 0.23\end{array}$

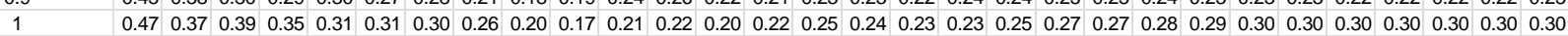



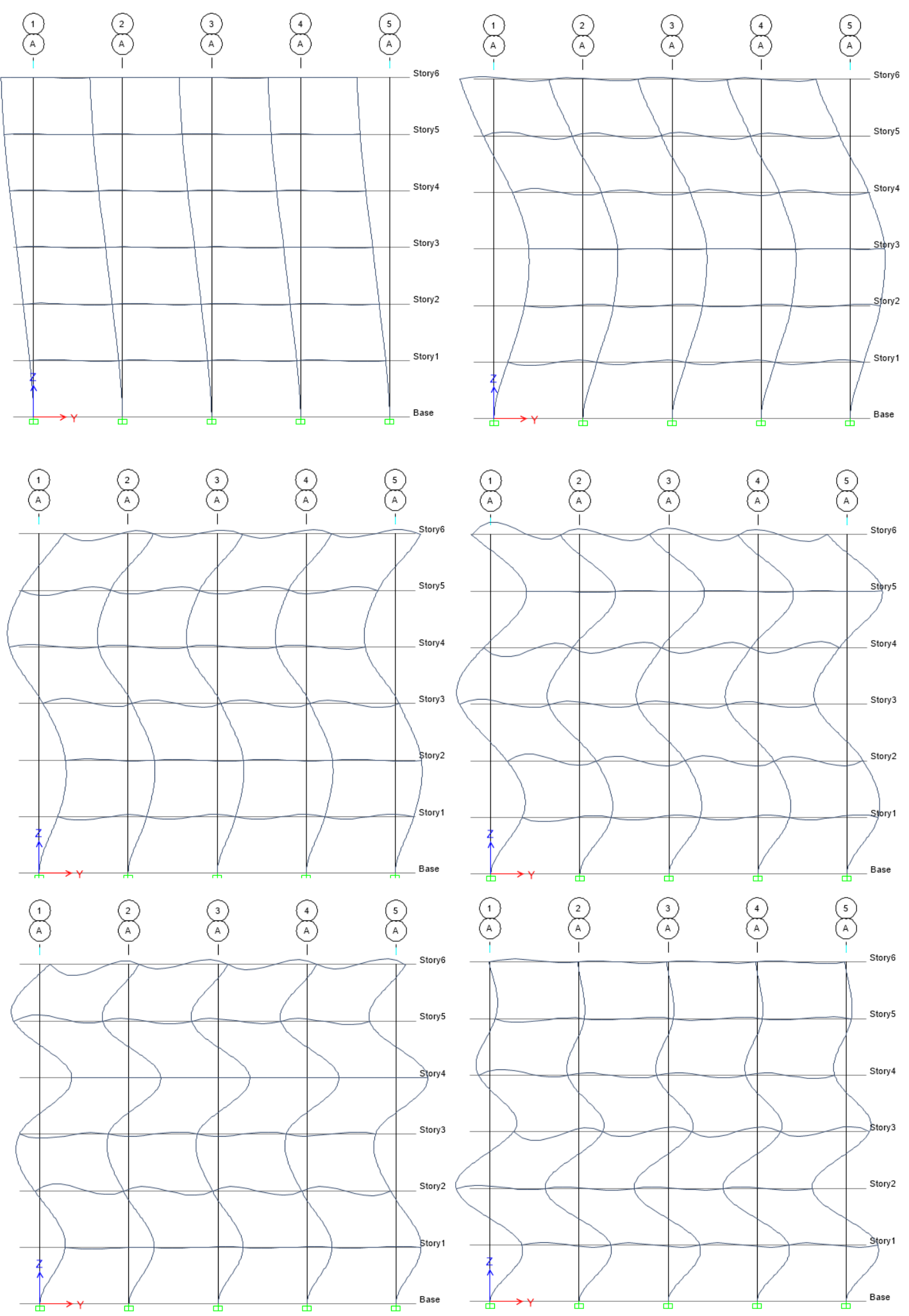

Figure A.3: Six initial mode shapes of the regular 6-story building. 